NIST

PUBLICATIONS

NIST Special Publication 808

\title{
Directory of Federal Government Laboratory Accreditation/Designation Programs
}




\section{NIST Special Publication 808}

\section{Directory of Federal Government Laboratory Accreditation/Designation Programs}

Maureen Breitenberg, Editor

Office of Standards Code and Information

National Institute of Standards and Technology

Gaithersburg, MD 20899

February 1991

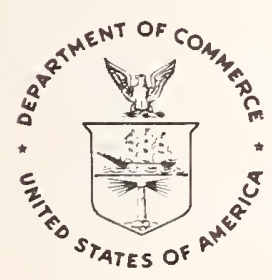

U.S. Department of Commerce

Robert A. Mosbacher, Secretary

National Institute of Standards and Technology John W. Lyons, Director 
National Institute of Standards and Technology Special Publication 808

Natl. Inst. Stand. Technol.

Spec. Publ. 808

105 pages (Feb. 1991)

CODEN: NSPUE2
U.S. Government Printing Office

Washington: 1991
For sale by the Superintendent of Documents U.S. Government Printing Office Washington, DC 20402 
This directory is designed to provide updated information on laboratory accreditation and similar types of programs conducted by the federal government. These programs designate a set of laboratories or other entities to conduct testing to assist federal agencies in carrying out their responsibilities. The programs include an assessment regarding the capability of the laboratory to conduct the testing. The type and degree of such assessments, however, vary greatly by program.

Laboratory accreditation and related efforts provide varying degrees of assurance regarding the technical proficiency and competence of a entity to assess a product's or service's conformance to a set of prescribed standards. Many sectors of the economy may be interested in laboratory accreditation and related programs for a variety of economic, procurement, safety, or other considerations. Mutual acceptance of laboratory test results between countries can also serve as a basis for increased opportunities for international trade.

Federal, state, and local government officials, manufacturers, distributors, and others may find the information contained in this directory of use in identifying pertinent federal laboratory accreditation/designation programs and their details, as weil as in finding a contact point within the appropriate agency. It should be noted that the entries in this directory are based primarily on information provided by the federal agency and reflect the agency's view of its activities. Parties interested in this area may also wish to review NBS SP 739, Directory of Federal Government certification Programs, which contains information on a number of closely related programs. 


\section{ACKNOWLEDGMENTS}

This directory is based on earlier publications in the field by Charles $W$. Hyer, who was responsible for identifying many of the programs included in this report. The United States General

Accounting office Report, "GAO/RCED-89-102, Laboratory Accreditation: Requirements Vary Throughout the Federal Government," was also very useful in preparing this directory.

Special thanks are due to Nancy Trahey, the National Voluntary Laboratory Accreditation Program (NVLAP), for her review of this document and to all the program officials who provided the information contained in this directory, without which this publication would not have been possible.

Maureen Breitenberg

Editor 


\section{ABSTRACT}

This directory is designed to provide updated information on federal government laboratory accreditation and similar type programs conducted by the federal government. These programs designate a set of laboratories or other entities to conduct testing to assist federal agencies in carrying out their responsibilities. The programs include an assessment regarding the capability of the laboratory to conduct the testing. The type and degree of such assessments, however, vary greatly by program. It should be noted that the entries in this directory are based primarily on information provided by the federal agency and reflect the agency's view of its activities. Parties interested in this area may also wish to review NBS SP 739, Directory of Federal Government Certification Programs, which contains information on a number of closely related programs.

This directory is part of ongoing NIST efforts to establish and maintain comprehensive databases on standards, regulations, laboratory accreditation and certification programs and related information in accordance with the requirements of the Trade Agreements Act of 1979. This material has been compiled to meet the needs of government, industry, and the public for information on U.S. Government laboratory accreditation and related programs.

Key Words: certification; grading; inspection; laboratory accreditation; listing; mutual recognition schemes; proficiency testing; qualified laboratories; standards; testing 



\section{CONTENTS}

Page

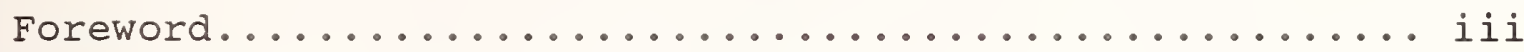

Acknowledgments............................ iv

Abstract................................... v v

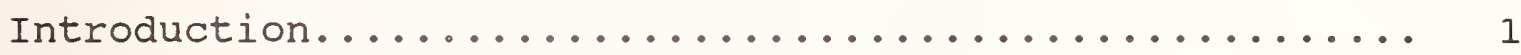

Programs by Department/Agency.................... 6

Appendix I ---- Indices....................... 71

Government National Accreditation systems.......... 72

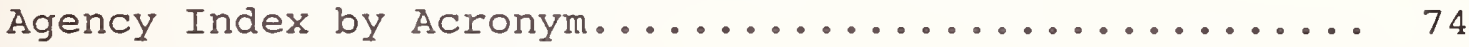

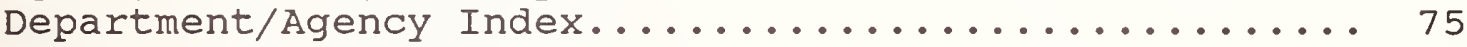

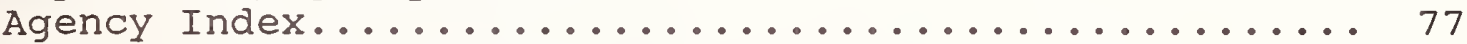

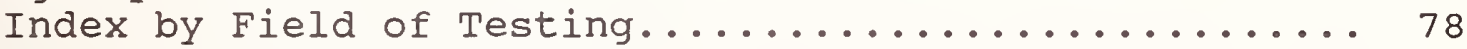

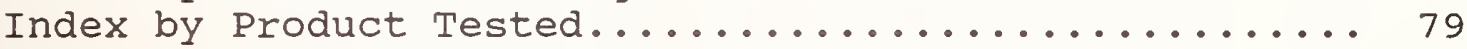

Appendix II --- Format Used for Each Entry.......... 83

Appendix III -- Other Programs of Possible Interest..... 85

Appendix IV --- List of Acronyms................. 93

Appendix V ---- Other NIST Documents of Possible Interest 95 



\section{INTRODUCTION}

\section{Background}

Laboratory accreditation has taken on increased significance worldwide as international recognition and acceptance of national accreditation bodies have assumed greater importance in the reduction of technical barriers to trade. Laboratory accreditation provides varying degrees of assurance of the technical proficiency and competence of a laboratory to assess a product's or service's conformance to a set of prescribed standards. 1 The competence of laboratories which perform the required testing within a certification or approval system is as vital in securing acceptance of the results of that certification/approval as is the adequacy of the standards on which the certification is based. The effects of laboratory accreditation, certification, and standardization activities are intertwined and together can serve as a basis for increased or diminished opportunities for international trade.

\section{Purpose of this Directory}

This directory is designed to provide information on federal laboratory accreditation and similar type programs which designate a set of laboratories or other entities to conduct testing to assist federal agencies in carrying out their responsibilities. The programs include an assessment regarding the capability of the laboratory to conduct the testing. The type and degree of such assessments, however, vary greatly by program. It should be noted that the entries in this directory are based primarily on information provided by the federal agency and reflect the agency's view of its activities. Parties interested in this area may also wish to review NBS SP 739, Directory of Federal Government certification Programs, which contains information on a number of closely related programs.

These accreditation/designation programs are conducted by the federal government for both products and services. The directory contains descriptions of each program, information on the date that the program was initiated, the authority under which the program is conducted, the fields of testing being accredited or designated, the products directly or indirectly affected by the testing, program requirements, availability of related publications, and other information.

1 Guide 2 of the International Organization for standardization notes that: "The term laboratory accreditation may cover the recognition of both the technical competence and the impartiality of a testing laboratory or only its technical competence. Accreditation is normally awarded following successful laboratory assessment and is followed by appropriate surveillance." 


\section{Directory Format}

The entries in this directory are organized by department or independent commission/agency. Within each department, programs are organized by departmental agency. There is a product index in Appendix I, in addition to several organizational indices. A description of the format used for each entry is contained in Appendix II.

Programs included within this directory are based primarily on a listing of federal laboratory accreditation programs included in a 1984 publication, Principal Aspects of U.S. Laboratory

Accreditation Systems, by Charles W. Hyer. A 1989 United States General Accounting Office Report, RCED 89-102, Laboratory Accreditation: Requirements Vary Throughout the Federal Government, updated that listing and identified 20 active federal laboratory accreditation programs. Thirty-one programs have been included in this directory based on information provided by the relevant department or agency.

Appendix III of the directory lists other federal agency programs of possible interest. This section includes programs which are very limited in the types and degree of assessment performed and whose managers did not feel that the program qualified as an accreditation program. This section also provides some information on programs which are still under development.

\section{Program Differences}

Requirements for laboratory accreditation/designation programs within the federal government vary greatly. Individual program requirements may include a review of documentation on aspects of an organization's structure; personnel; equipment and facilities; equipment calibration and maintenance procedures; quality control program; record keeping procedures; availability and use of operational/quality manuals; content and quality of actual test reports; testing conditions, methods and procedures; and/or sample handling and selection procedures. Accreditation/ designation procedures may also include an on-site inspection of the laboratory's equipment and facilities, or the use of a proficiency testing program.2 While some programs, such as those of the National Voluntary Laboratory Accreditation Program (NVLAP), are quite comprehensive, others involve only minimal review of a laboratory's competence. In general, the requirements of each program have been tailored to meet specific agency needs; and, except for the Department of Commerce's NVLAP, laboratory accreditation/designation is not the primary goal of the program.

2 Laboratory proficiency testing is defined by Iso Guide 2 as: "Determination of laboratory testing performance by means of interlaboratory test comparisons." 
The reader should not assume that comparable programs, even those which are conducted by the same department or agency, will include the same types or number of assessment procedures or will provide similar assurance regarding a laboratory's competency.

The following chart summarizes the number and types of assessment criteria and procedures required by the federal government laboratory accreditation type programs identified in this directory:

REQUIREMENT

\begin{tabular}{|c|c|c|c|}
\hline & $\underline{\text { YES }}$ & $\underline{\text { NO }}$ & $\underline{N} / \mathbf{A}$ \\
\hline Submission of Appropriate Documentation & 28 & 3 & \\
\hline Independence (No conflict-of-Interest) & 9 & 21 & 1 \\
\hline Financial Stability & 7 & 23 & 1 \\
\hline On-site Inspection & 26 & 5 & \\
\hline Staff Qualifications Requirements & 26 & 5 & \\
\hline Adequate Q.A. System & 23 & 8 & \\
\hline Sample control/Integrity Requirements & 21 & 10 & \\
\hline Recordkeeping Requirements & 26 & 5 & \\
\hline Test Report Content/Format Requirements & 24 & 7 & \\
\hline Available operational Manuals/Instructions & 21 & 10 & \\
\hline Periodic Random Re-audit of Facilities & 13 & 18 & \\
\hline Periodic Scheduled Re-audit of Facilities & 17 & 14 & \\
\hline Participation in Proficiency Testing Program & 18 & 13 & \\
\hline Adequacy of Facilities \& Equipment & 28 & 3 & \\
\hline Equipment Maintenance/Calibration Requirements & 25 & 6 & \\
\hline other & 6 & 25 & \\
\hline
\end{tabular}

All or most programs have equipment, facility, personnel, initial on-site inspection, and recordkeeping requirements. There are, however, considerable differences in requirements for laboratory independence from any direct control by the manufacturer/producer /user, the financial stability of the laboratory, for participation in a proficiency testing program and for re-audit requirements. In addition, some programs have other unique requirements, such as that the test station be open for public use, that the site of the test facility meet certain requirements, that the facility has adequate security, or that the laboratory has personnel available to testify in the event of a legal proceeding.

Another difference between programs is that some accredit laboratories in specific areas of testing (such as testing textiles and apparel products) or for specific test methods, while others accredit laboratories over a broader field of testing. 
Eligibility requirements for accreditation also vary among programs. Some programs restrict applications to state laboratories only. The Department of Agriculture (USDA) program for inspecting grain for export restricts the number of approved laboratories in a particular geographical area. Some accreditation programs are restricted to laboratories operated by the agency doing the accreditation, such as the Department of Veterans Affairs (VA) program to accredit the laboratories of its medical centers. This last type of program falls into a category somewhere between laboratory accreditation and internal quality assurance -- since elements of both are present.

The terminology used also varies among programs with some programs referring to a laboratory which meets the criteria established within the program as "accredited," to others that refer to the laboratory as "inspected," "accepted," "designated" or even "nationally recognized." Even the same term, such as "accredited," is used by different programs to mean very different types of assessments and assessment procedures. Different terms may also have different legal implications or may reflect differences between various agencies' legal authority to conduct specific programs. It is important that the reader be aware of such differences when reviewing the entries in this directory. The terminology used in individual entries, in some cases, was modified to reflect the needs and preferences of the agency.

\section{Multiple Accreditations}

As noted in the recent GAO report, "many kinds of laboratories and organizations perform testing to ensure compliance with government requirements, including clinical laboratories that test human tissue for disease; environmental laboratories that test water for chemicals and bacteria; food laboratories that test meat and poultry for moisture, fat, protein, and salt; and commercial gauger laboratories that test petroleum products and other merchandise for composition and/or characteristics." Laboratories involved in multiple types of testing, in some cases, may be accredited by more than one agency. Because the government laboratory accreditation programs (except for the NVLAP program) are narrowly focused -- accrediting or designating laboratories to test only a narrowly defined range of products or services -- it is unlikely that a laboratory would be accredited/ designated to perform the same type of testing by more than one government agency. 
The subject of overlapping accreditations was explored in the GAO report, and only two programs (one operated by the Federal

Communications Commission and the NVLAP program) showed some limited overlap.

Acceptance of Accreditation Program Results by other Federal Agencies

Some federal laboratory accreditation programs are accepted by other agencies. Participation in the NVLAP program, for example, is required by the Department of Housing \& Urban Development (HUD), the Federal Communications Commission (FCC), the Federal Trade Commission, the Environmental Protection Agency (EPA), the Nuclear Regulatory Commission (NRC), and parts of the Department of Defense (DOD). Reports on laboratories (that also test pesticides and environmental contaminants) from the Food \& Drug Administration's (FDA's) toxicology laboratory monitoring program are shared with the Environmental Protection Agency (EPA).

Again, because accreditation programs are usually narrowly focused and limited to one agency's area of responsibility, the results of laboratory assessments from these programs are usually of only limited use to other federal agencies.

\section{Directory Changes}

Federal government agencies are encouraged to notify NIST of any changes in their laboratory accreditation programs or of new programs. Such information should be sent to:

Office of Standards code \& Information

National Institute of Standards \& Technology

Administration Building, Room A629

Gaithersburg, MD 20899

(301) 975-4031

\section{Other References}

Additional NIST documents of possible interest are contained in Appendix $V$. 
Department/Agency: Department of Agriculture (USDA)

Received: $10 / 90$

Animal \& Plant Health Inspection service (APHIS)

Veterinary Service (VS)

Science and Technology

Room 16308 SB

14th and Independence Avenue, SW

Washington, DC 20250

Phone: $\quad$ (202) $447-2081$

FAX:

(202) 475-4265

Program Title: Accreditation of laboratory facilities for contagious equine metritis (CEM).

Date Established: April 1983.

Description: To approve laboratories to conduct diagnostic procedures for contagious equine metritis, a highly transmissible venereal disease of horses.

Fields of Testing: Biological.

Products Tested: Equine-related products (specimens conducted from the reproductive tract of horses).

Standards/Test

Methods:

See 9 CFR Part 92 and VS Memorandum 558.2, 5/18/81.

A list, is available from USDA/APHIS, Import-Export Animals Staff, Room 764, 6505 Belcrest Road, Hyattsville, MD 20782.

Assessment

Criteria/

Procedures:

Submission of Appropriate Documentation

Independence (No Conflict-of-Interest)

Financial stability

On-site Inspection (includes complete audit of capabilities)

Staff Qualifications Requirements

Adequate Q.A. System

Sample Control/Integrity Requirements

Recordkeeping Requirements

Test Report Content/Format Requirements

Available Operational Manuals/Instructions

Periodic Random Re-audit of Facilities

Periodic Scheduled Re-audit of Facilities

Participation in a Proficiency Testing Program $\frac{x}{x}$

Adequacy of Facilities \& Equipment

Equipment Maintenance/Calibration Requirements

$\underline{x}$

other

Other Information: The criteria for accreditation are comparable to those suggested in the American Society of Testing and Materials (ASTM) E548, "Practice for Preparation of Criteria for Use in the Evaluation of Testing and Inspection Bodies." They are also similar to the EC requirements.

Accreditation

Terminology:
Uses the term, "approved," which is defined as the assurance of a laboratory's competence to run approved tests and that adequate space and equipment is available. 


$\begin{array}{ll}\text { Compliance: } & \text { Mandatory. } \\ \text { Authority: } & 9 \text { CFR Part } 92 \text { and VS Memorandum 558.2, 5/18/81. } \\ \text { Fees: } & \text { None. }\end{array}$

Accreditation

Action Frequency: Good until revoked.

Assessors: On-site inspection done by APHIS field Veterinary Medical

officers. Credentials reviewed by Head, General Bacteriology section.

Proficiency

Testing Program: Ongoing as required.

Appeal Procedure: Normal U.S. federal agency due process appeals mechanisms.

Publications: All standards and program notices and changes are published in the Federal Register.

Logo: None.

No. of Labs: 23 laboratories as of March 1990.

Availability of Accreditation:

Open to all U.S. private and state govermment laboratories.

List/Directory of A list, "Contagious Equine Isolation Approved Laboratories," Accredited Labs: is available from USDA/APHIS.

Int'l Recognition/ No special arrangements. System is an importer assistance Agreements: program.

Other Recognition: None. 
Department/Agency: Department of Agriculture (USDA)

Received: $4 / 90$

Federal Grain Inspection Service (FGIS)

Compliance Division

P.O. Box 96454

Washington, DC 20090-6454

Phone:

Program Title:

Description:
Date Fstablished:

(202) 447-8525

Grain and commodity inspection and weighing (including equipment, scale and weight testing).

1977 (some aspects of the program were begun earlier).

Approves federal and state governmental units and private sector agencies to inspect and weigh grains and test equipment and weights under the U.S. Grain Standards Act and approves federal units to inspect and weigh commodities under the Agricultural Marketing Act of 1946.

Fields of Testing: Biological, chemical, mechanical and metrology.

Products Tested: Grain, conmodities, weighing and measurement equipment.
Standards/Test Methods:

Assessment Criteria/ Procedures:

Aocreditation Terminology:

U.S. Grain Standards Act, as amended, and applicable regulations; the official U.S. Standards for Grain; FGIS Inspection Handbooks; FGIS Weighing Handbook; and related instructions. List is available from FGIS.

Submission of Appropriate Documentation Independence (No Conflict-of-Interest) Financial Stability On-site Inspection Staff Qualifications Requirements Adequate Q.A. System Sample Control/Integrity Requirements Recordkeeping Requirements Test Report content/Format Requirements Available Operational Manuals/Instructions Periodic Random Re-audit of Facilities Periodic Scheduled Re-audit of Facilities Participation in a Proficiency Testing Program $\frac{x}{x}$ Adequacy of Facilities \& Equipment Equipment Maintenance/Calibration Requirements $\underline{x}$ other

other Information: The criteria for accreditation are comparable to those suggested in the American Society of Testing and Materials (ASTM) E548, "Practice for Preparation of Criteria for Use in the Evaluation of Testing and Inspection Bodies."

Uses the terms, "designated/delegated," which are defined as a person or agency which has adequate facilities and qualifications for the performance of such official inspection and weighing functions and meets other criteria. 
Campliance:

Authority:

Fees:

Accreditation

Action Frequency:

Assessors:

Proficiency

Testing Program:

Appeal Procedure:

Publications:

Logo:

No. of Labs:

Availability of Accreditation:
Mandatory for official inspection and weighing services under the Act.

United States Grain Standards Act, as amended, 7 USC 71 et seq.; regulations are contained in 7 CFR Parts 800-810; Agricultural Marketing Act, 7 USC 1621 et. seq.; regulations are contained in 7 CFR Part 68.

Fees are charged to the accredited agencies to cover FGIS costs. Only fees that are approved by FGIS as being reasonable and nondiscriminatory may be charged by an agency for official service.

Ongoing for FGIS and certain state entities - others are reissued every 3 years or more often if needed, provided requirements are met.

FGIS personnel.

Randomly selected samples are monitored for accuracy.

Normal federal due process appeals exist for accredited agencies. Appeals for weighing and measurement results may be appealed to FGIS.

U.S. Grain Standards Act, as amended, and applicable regulations; the official U.S. Standards for Grain; FGIS Inspection Handbooks; FGIS Weighing Handbook; and related instructions are available from FGIS.

An "Official mark" or "shield" prescribed by USDA/FGIS shall be printed on all official inspection certificates.

107 laboratories as of 3/26/90.

open to all U.S. private sector and state laboratories, though each delegated/designated agency has an exclusive territory, limiting the number of laboratories approved in a particular area.

List of delegated/designated agencies and field offices is available from FGIS.
Int'1 Recognition/ Agreements:

Other Recognition:
FGIS and certain delegated states inspect export grain.

Program is recognized by FDA, ASCS/USDA, and APHIS/USDA and in the scale testing area by NIST. There are mutual recognition agreements in place with NIST and FDA. 
Department/Agency: Department of Agriculture (USDA)

Received: $3 / 90$

Food Safety \& Inspection Service (FSIS)

Science \& Technology, Chemistry Division

12th \& C Streets, SW

Washington, DC 20250

Phone: $\quad 202-447-5850$

FAX: $\quad 202-447-2257$

Program Title: Accredited laboratory program.

Date Established: 1962.

Description: Accredits domestic nonfederal analytical chemistry laboratories to analyze meat and poultry food products for moisture, protein, fat and salt content, and/or certain specific classes of chemical residues. Currently the specific chemical residues are: chlorinated hydrocarbons, polychlorinated piphenyls, sulfonamides, nitosamimes and arsenic.

Fields of Testing: Chemical.

Products Tested: Meat and poultry food products only.

standards/Test Requirements for accreditation are contained in 9 CFR Parts Methods: 318 and 381.

Assessment Criteria/ Procedures:

Submission of Appropriate Documentation Independence (No Conflict-of-Interest) Financial Stability on-site Inspection Staff Qualifications Requirements Adequate Q.A. System Sample Control/Integrity Requirements Recordkeeping Requirements

Test Report content/Format Requirements Available Operational Manuals/Instructions Periodic Random Re-audit of Facilities Periodic Scheduled Re-audit of Facilities Participation in a Proficiency Testing Program $\frac{x}{x}$ Adequacy of Facilities \& Equipment Equipment Maintenance/Calibration Requirements $\frac{x}{x}$ Other

Other Information: The requirements are comparable to the guidelines suggested in the American Society of Testing and Materials (ASTM) E548, "Practice for Preparation of Criteria for Use in the Evaluation of Testing and Inspection Bodies."

Accreditation Terminology:
Uses the term, "accredited," which means a nonfederal analytical laboratory that has met the requirements for accreditation .... and may be used in lieu of an FSIS laboratory for analyzing official regulatory samples. 
Campliance: Voluntary.

Authority: $\quad 9$ CFR Parts 318 and 381.

Fees: $\quad$ No laboratory fees.

Accreditation Accreditation is continuous. However, accreditation will be Action Frequency: withdrawn under 9 CFR Rules if the laboratory fails to meet the requirements of the rules.

Assessors: USDA/FSIS personnel who are fully trained and experienced in laboratory review techniques.

Proficiency

Testing Program:

A mandatory aspect of the program is the split sample analytical capability review. Both as initial and continued, the reference sample program constitutes the major accreditation criteria method.

Appeal Procedure: Normal U.S. federal agency due process appeals mechanisms. Additional appeals procedures are spelled out in 52 FR 9202.

Publications: The Federal Register Notice of January 28, 1987.

Logo:

None, though the accredited laboratory may say that it is "USDA-FSIS accredited for XXX." (XXX must be a specific statement)

NNo. of Labs:

Approximately 310 laboratories as of January 4, 1990.

Availability of Accreditation:

Open to domestic private sector and state govermment laboratories.

List/Directory of Accredited Labs:

Meat and Poultry Inspection Directory.

Int'1 Recognition/ Program is recognized by some foreign countries. There are Agreements: no mutual recognition arrangements with foreign governments, though some foreign govermments require the U.S. meat program to offer such a program. Likewise the U.S. govermment would like other govermments to have similar programs.

Other Recognition: Program is recognized by all states. 
Department/Agency: Department of Agriculture (USDA)

Received: $3 / 90$

Office of Transportation (OT)

ATP Manager

P.O. Box 96575

Washington, DC 20090-96575

Phone: $\quad$ (202) $653-6310$

FAX: $\quad$ (202) 653-6327

Program Title: Agreement on the International Carriage of Perishable Foodstuffs and on the Special Equipment to be Used for such Carriage (ATP).

Date Established: 1986.

Description: The ATP is an international agreement which sets standards for the testing and uses of equipment which carries perishable foodstuffs. The United States is a signatory to this agreement; and, as such, certifies ATP test stations and laboratories.

Fields of Testing: Thermal.

Products Tested: Truck trailers, railcars, freight containers, refrigeration units or other equipment used for the transport of perishable foodstuffs.

Standards/Test Methods:

The Agreement and 7 CFR Part 3300 define all the acceptance criteria. A list may be obtained from the ATP Manager at the above address.

Assessment

Submission of Appropriate Documentation

Criteria/

Procedures:

Independence (No conflict-of-Interest)

Financial stability

On-site Inspection

Staff Qualifications Requirements

Adequate Q.A. System

Sample Control/Integrity Requirements

Recordkeeping Requirements

Test Report Content/Format Requirements

Available Operational Manuals/Instructions

Periodic Random Re-audit of Facilities

Periodic Scheduled Re-audit of Facilities

Participation in a Proficiency Testing Program

Adequacy of Facilities \& Equipment

Equipment Maintenance/Calibration Requirements

other - test station must be open for public use

and costs of test must be reasonable. $\quad \mathrm{x}$

Other Information: The requirements for certification are similar to those contained in the American Society of Testing and Materials (ASTM) E548, "Practice for Preparation of Criteria for Use in the Evaluation of Testing and Inspection Bodies," except that there are no personnel qualifications requirements. The requirements follow those of the ATP agreement, which is negotiated among the contracting parties. 
Accreditation

Terminology:

campliance:

Authority:

Fees:

Aocreditation

Action Frequency

Assessors:

Proficiency

Testing Program: None.

Appeal Procedure: Normal U.S. federal agency due process appeals mechanisms,

Publications:

Logo:

No. of Labs:

Availability of Aocreditation:

List/Directory of Accredited Labs:

Int'l Recognition/ Agreements:

Uses the term, "approved," which means a facility which meets the requirements of the Agreement and 7 CFR Part 3300.

Mandatory for facilities wishing to issue ATP certificates.

7 CFR Part 3300 and the Intermational Carriage of Perishable Foodstuffs Act of 1982, P.L. 97-325.

Fees are set by and paid to testing station/laboratory.

Test stations must be reaccredited every 5 years.

ATP Manager.

Lists of approved test facilities and the text of the ATP agreement is available from the ATP Manager at the above address.

None for the test facility, an ATP Placard showing the information obtained from the test procedure may be attached to the certified equipment.

Two test facilities as of March 15, 1990.

open to all U.S. federal, state and private sector laboratories.

\section{A list is contained in "ATP Test stations."}

U.S. ATP certificates are recognized by other ATP signatories including Austria, Belgium, Czechoslovakia, Dermark, Finland, France, F.R. of Germany, Hungary, Ireland, Italy, Luxembourg, Morocco, Netherlands, Norway, Poland, Portugal, Spain, Sweden, U.K., U.S., and Yugoslavia under a reciprocal arrangement. 
Department/Agency: Department of Commerce (DOC)

Received: $3 / 90$

National Institute of Standards \& Technology (NIST)

Office of Weights \& Measures (OWM)

Bldg. 101, Room A

Gaithersburg, MD 20899

Phone:

FAX:

Tellex:

Program Title: State laboratory program.

Date Established: 1967.

Description:

$301-975-4014$

301-963-2871

TRT 197674 NIST UT
Provides a system for certifying state weights and measures laboratories by specific measurement areas. Authorizes state laboratories to conduct initial evaluation of weighing and measuring devices/systems under the National Type Evaluation Program (NTEP) before their use in commerce.

Fields of Testing: Metrology (mass, volume, length, temperature (Iiquid in-glass)).

Products Tested: Reference standards in the above areas, weighing and measuring devices/systems.

Standards/Test

Methods:

These are contained in NIST Handbooks 143 and 145.

Assessment Criteria/ Procedures:

Submission of Appropriate Documentation Independence (No Conflict-of-Interest) Financial Stability on-site Inspection Staff Qualifications Requirements Adequate Q.A. System Sample Control/Integrity Requirements Recordkeeping Requirements Test Report Content/Format Requirements Available operational Manuals/Instnuctions $\frac{x}{x}$ Periodic Random Re-audit of Facilities Periodic Scheduled Re-audit of Facilities $\frac{\mathrm{x}}{\mathrm{x}}$ Participation in a Proficiency Testing Program $\frac{\mathrm{x}}{\mathrm{x}}$ Adsquacy of Facilities and Equipment Equipment Maintenance/Calibration Requirements $\underline{x}$ other

Other Information: Each state must have a trained metrologist and an adequate laboratory facility and must demonstrate on a continuing basis that it is capable of providing valid measurements in order to be certified in a particular measurement area. The criteria are comparable to the requirements of the American Society of Testing and Materials (ASTM) E548, "Practice for Preparation of Criteria for Use in the Evaluation of Testing and Inspection Bodies." A quality assurance program is contained in Handbook 143, Appendix D. Requirements are also comparable 
Accreditation

Terminology:

Compliance:

Aurthority:

Fees:

Accreditation

Action Frequency: Normally every 3 years, but may be annually.

Assessors:

Proficiency

Testing Program: a laboratory appears to have the capability to perform Handbook 143.

Voluntary.

NIST Mission Statement.

None.

Office of Weights and Measures staff. to EN 45001, except that the assessors are NIST/OWM staff and are not "appointed," except as "assigned." Subcontracting sections are also not applicable.

Uses the term, "certified," which means the recognition that a reliable measurements in specific measurement areas and meets the general and specific requirements described in NIST

Measurement control (both internal and external) have been established for mass calibration and the volume transfer testing of glass standards. Internal measurement control programs consist of repeated measurements on the same objects over an extended period of time. In external measurement control programs, standards external to the laboratory are submitted to the laboratory for test. These standards are usually calibrated by NIST to provide a reference value. These programs are expected to be expanded into other areas. Round robin experiments are conducted to investigate the agreement of state laboratories in other measurement areas.

Appeal Procedure: Normal U.S. federal agency due process appeals mechanisms.

Publications: Requirements are contained in NIST Handbooks 143 and 145.

Logo: None.

No. of Labs: 51 laboratories as of March 28, 1990.

Availability of Aocreditation:

open to all. state govermment laboratories.

List/Directory of NIST SP 686 - State Weights and Measures Laboratories: Program Aocredited Labs: Description and Directory.

Int'l Recognition/

Agreements: None.

Other Recognition: Recognized by all states and the USDA/FGIS. 
Department/Agency: Department of Commerce (DOC)

Received: $6 / 90$

National Institute of Standards \& Technology (NIST)

National Voluntary Laboratory Accreditation Program (NVLAP) Bldg. 411, Room Al24

Gaithersburg, MD 20899

Phone: $\quad 301-975-4016$

FAX: $\quad 301975-3839$

Program Title: National Voluntary Laboratory Accreditation Program (NVLAP)

Date Established: Formal procedures published February 25, 1976.

Description: Accredits public and private testing laboratories based on evaluation of their technical qualifications and competence for conducting specific test methods in specified fields of testing.

Fields of Testing: All fields for which a need has been demonstrated.

Products Tested: current areas include: acoustical testing services; bulk and airborne asbestos fiber analysis; carpet testing; thermal insulation materials testing; construction testing services, including concrete, cement, aggregates, road/paving materials, admixtures, soil and rock, and geotextiles; computer applications, including: GOSIP, POSIX and X.25; solid fuel room heaters; personnel radiation dosimetry processing; radiation dosimetry calibration; commercial products testing including paint, paper, seals and sealants, plastic, and plumbing fixtures; electromagnetic compatibility and telecommunications testing according to FCC and Mil std 462 requirements.

Standards/Test Methods:

The entire NVLAP procedure is based upon the premise that accreditation will be to already published standards, which are of importance to commerce, consumer well being, or the public health and safety. A published list of requirements is available from the above address.

Assessment

criteria/

Submission of Appropriate Documentation

Independence (No Conflict-of-Interest)

Procectures:

Financial Stability

on-site Inspection

Staff qualifications Requirements

Adequate Q.A. System

Sample Control/Integrity Requirements

Recordkeeping Requirements

Test Report content/Format Requirements

Available Operational Manuals/Instructions

Periodic Random Re-audit of Facilities

Periodic Scheduled Re-audit of Facilities

Participation in a Proficiency Testing Program

Adequacy of Facilities \& Equipment

Equipment Maintenance/Calibration Requirements

$\frac{\frac{x}{\frac{x}{x}}}{\frac{x}{\frac{x}{x}}} \frac{\frac{x}{x}}{\frac{x}{x}} \frac{\frac{x}{x}}{\frac{x}{x}}$

Other 
Other Information: The requirements of the American Society of Testing and Materials (ASTM) E548, "Practice for Preparation of Criteria for Use in the Evaluation of Testing and Inspection Bodies," were patterned after the NVLAP procedures. NVLAP requirements are also comparable to ISO Guides 25, 38, 54, and 55 and the Iso 9000 Series standards.

Accreditation Terminology:

campliance:

Authority:

Fees:

Accreditation

Action Frequency: Accreditation is reissued annually.

Assessors:

Proficiency

Testing Program:

Appeal Procedure:

Publications:

Logo:

No. of Labs:

Availability of Accreditation:

List/Directory of Accredited Labs: tests or types of tests.

Voluntary.

15 CFR Part 7. and are set by the agency. under specified conditions. laboratories.
Uses the term, "accredited," which means formal recognition that a testing laboratory is competent to carry out specific

Fees and charges to the laboratory participants cover the costs of examining, accrediting, and auditing the laboratories

NVLAP uses technical experts recognized in a particular field of testing, who are under contract to NVLAP.

A program policy is to employ proficiency testing and reference sample procedures wherever practical and useful.

The laboratory has 30 days to appeal the suspension or revocation of their accreditation. A hearing will be held under 5 USC 556. Agency also employs other normal U.S. federal agency due process appeals mechanisms.

Copies of 15 CFR, Part 7, the "NVLAP Directory of Accredited Laboratories," and "Program Handbooks" specific to each field of testing are available from the above address.

Upon accreditation, the laboratory may use the "NVLAP" logo

Approximately 891 accredited laboratories as of March 1, 1990. There are over 1100 laboratories involved in the program.

open to all U.S. and foreign, private sector and government

"Directory of NVLAP Accredited Laboratories." 
Int'1 Recognition/ NVLAP has Memoranda of Understanding (MOU's), which provide Agreements:

for mutual recognition of accredited laboratories. Agreements are in effect between the United States and the National Association of Testing Laboratories (NATA) in Australia, the Testing Laboratory Registration council (TELARC) in New Zealand, and the Standards Council of Canada (SCC),

Other Reosgnition: The NVLAP programs for accrediting carpet, asbestos, and dosimetry laboratories are recognized by the Department of Housing and Urban Development (HUD), the Environmental Protection Agency (EPA), and the Nuclear Regulatory Commission (NRC) respectively. 
Department/Agency: Department of Defense (DOD)

Received: $7 / 90$

Army Corps of Engineers (CE)

ATTN: DAEN-CECW-EG

Washington, DC 20314-1000

Phone:

Program Title:

Date Established:

Description:
$202-272-0207$

CE district, project and commercial laboratories assurance inspection program.

1966.

The district engineer is responsible for assuring that district, project and commercial laboratories performing materials testing for the corps of Engineers have the required capability. Each district requests assurance inspections of their testing laboratories by the division materials laboratory. Division materials laboratories are inspected by cement and concrete Reference Laboratory, NIST.

Fields of Testing: Mechanical and chemical.

Products Tested:

Soil; aggregates; stone; sand, cement and cement based products including: concrete, lime, gypsum, building constructions (including foundations), and water, air, and components of the enviroment.

Standards/Test Methods:

Assessment Criteria/ Procedures:

Other Information
ASTM Standard E329; "Recommended Practice for Inspection and Testing Agencies for Concrete, Steel, and Bituminous Materials as Used in Construction," Engineer Manual 1110-2-1906 , Corps of Engineers Waterways Experiment Station Handbook for concrete and cement, or project specifications as applicable.

Submission of Appropriate Documentation Independence (No conflict-of-Interest) Financial stability On-site Inspection Staff Qualifications Requirements Adequate Q.A. System Sample Control/Integrity Requirements Recordkeeping Requirements Test Report Content/Format Requirements Available Operational Manuals/Instructions Periodic Random Re-audit of Facilities $\begin{array}{ll}\text { Periodic Scheduled Re-audit of Facilities } & \frac{\mathrm{x}}{\mathrm{x}} \\ \text { Participation in a Proficiency Testing Program }\end{array}$ Adequacy of Facilities \& Equipment $\frac{x}{x}$ Equipment Maintenance/Calibration Requirements $\frac{x}{x}$ other

Human resources, physical resources, quality systems requirements follow the American Society of Testing and Materials (ASTM) E548, "Practice for Preparation of Criteria for Use in the Evaluation of Testing and Inspection Bodies," and are then specifically amplified by the ASTM standard E329, 
Compliance:

Authority:

Accreditation

Action Frequency:

Assessors:
"Recommended Practice for Inspection and Testing Agencies for Concrete, Steel, and Bituminous Materials as Used in construction."

Inspection of contracted, district or project laboratories is required prior to testing and at least every 2 years thereafter (Engineer Regulation 1110-1-261). Laboratories for testing concrete, steel, and bituminous materials are inspected for compliance with ASTM E329 or project specifications. Laboratories for testing soils and rock shall be inspected for compliance with ASTM D3740 and applicable tests in Engineer Manual 1110-2-1906 or tests required by project specifications, corps of Engineers Waterways Experiment Station Handbook for Concrete and cement.

Laboratories engaged in analysis of water, sediment or other samples for chemical analysis are inspected to assure capability using procedures described in Handbook for Analytical ouality control in Water and Wastewater Laboratories, EPA 600/4-790919, March 1979; National Handbook of Recommended Methods for Water Data Acquisition, USGS 1977; "Guidelines for Establishing Test Procedures for Analysis of Pollutants Under the Clean Water Act," 40 CFR Part 136, Vol. 50, No 209; Test Methods for Evaluating Solid Wastes, EPA SE-846, April 1984; Standard Methods for the Examination of Water and Wastewater, 1985, APHA, AWWA, \& WPCF, American Public Health Association; Procedures of Sediment and Water Samples, EPA/CE-81-1, 1981, Waterways Experiment Station; Engineer Regulation 1110-1-263, "Chemical Data Quality Management for Hazardous Waste Remedial Action."

Mandatory for testing to corps of Engineers requirements.

Engineer Regulation No. 1110-1-261.

\section{Every 2 years.}

District laboratories will be inspected by qualified personnel from the division laboratory; division laboratories will be inspected by NIST cement and concrete Laboratory. (Engineer Regulation No. 1110-1-8100.

Proficiency

Testing Program: Depends on the type of laboratory. See other Information.

Appeal Procedure: Normal U.S. federal agency due process appeals mechanisms.

Publications: See other Information.

Logo: None.

No. of Labs: Estimated at over 100 laboratories on a national basis, however, an exact count would require a survey of each district. 
Availability of

Accreditation: Open to district, contracted and project laboratories.

List/Directory of

Accredited Labs: None.

Int'l Recognition/

Agreements: None intended or expected.

Other Recognition: None. 
Department/Agency: Department of Defense (DOD)

Received: $9 / 90$

Defense Electronics Supply Center (DESC)

Qualification Division (EQ)

1507 wilmington Pike

Dayton, OH 45444

Phone: $\quad 513-296-6271$

FAX: $\quad 513-296-8748$

Date Established: 1962-assumed from ASESA program of 1940s.

Description: Determines that conmercial laboratories are suitably

equipped to perform specific testing for manufacturers listed on Qualified Product/Manufacturer Lists (QPL/QML).

Fields of Testing: Electrical, ionizing radiation, metrology, non-destructive, optics and photometry.

Products Tested: Military devices and components.

Standards/Test Military standards and specifications with appropriate federal Methods: and commercial standards and test methods. See Legal Authority.

Assessment

Submission of Appropriate Documentation

Criteria/

Independence (No Conflict-of-Interest)

Procedures:

Financial stability

On-site Inspection

Staff qualifications Requirements

Adequate Q.A. System

Sample control/Integrity Requirements

Recordkeeping Requirements

Test Report content/Format Requirements

Available Operational Manuals/Instructions $\quad \frac{\mathrm{x}}{\mathrm{x}}$

Periodic Random Re-audit of Facilities $\frac{x}{x}$

Periodic Scheduled Re-audit of Facilities $\frac{x}{x}$

Participation in a Proficiency Testing Program

Adequacy of Facilities \& Equipment

Equipment Maintenance/Calibration Requirements $\underline{\mathrm{x}}$

other

Other Information: Emphasis is placed on the physical resources of the entity to be approved. Human and organizational resources follow the guidelines of the American Society of Testing and Materials (ASTM) E548, "Practice for Preparation of Criteria for Use in the Evaluation of Testing and Inspection Bodies."

Accreditation

Terminology:

Compliance:
Uses the term, "suitable," which means that the laboratories are found to be suitably equipped and staffed for performing qualification testing for manufacturers.

Mandatory. 
Authority: $\quad$ Defense procurement approval requirements of Defense Acquisition Regulation (DAR) and DOD Directive 4120.3-M; qualification Information for Manufacturers, Qualification Handbook for Established Reliability Specifications, and SD-6 Provisions Governing Qualifications.

Fees: None.

Accreditation

Action Frequency: Accreditation is reissued every 2 years.

Assessors: Qualified DESC-EQ engineers.

Proficiency

Testing Program: As required by standards or specifications.

Appeal Procedure: Normal U.S. federal agency due process appeals mechanisms.

Publications: Qualified Product Lists (QPL's); DOD Standardization Manual 4120.3-M; SD-6 Provisions Governing Qualifications and the "List of Commercial Laboratories Suitable for Testing Military Devices" are available.

Logo: None for laboratories. Most components will be marked with the military $\mathrm{P} / \mathrm{N}$ and "JAN" brand.

No. of Labs: Approximately 111 laboratories as of September 17, 1990.

Availability of Accreditation:

List/Directory of Accredited Iabs: open to all U.S. and foreign private sector laboratories.

"List of Commercial Laboratories Suitable for Testing Military Devices."

Int'1 Recognition/ Recogmition agreements include NATO-STANAG 4093; U.S.-Canada, Agreements: U.S.-Ireland, and U.S.-Australia international standardization agreements.

Other Recognition: None. 
Department/Agency: Department of Defense (DOD)

Received: $8 / 90$

Defense Logistics Agency (DLA)

Defense Personnel support Center (DPSC)

2800 South 20th Street

Philadelphia, PA 19101

$\begin{array}{ll}\text { Phone: } & 215-737-3240 \\ \text { FAX: } & 215-737-3806\end{array}$

Telex:

Program Title: Qualified Laboratory List (QLL)

Date Established: 1961.

Description: Lists laboratories found to be capable of performing types of specification tests for clothing, textiles, footwear, and equipage-type items. DPSC is presently in the process of revising the program to reduce the nonconformance rate for suppliers' laboratory reports.

Fields of Testing: Chemical, electrical, non-destructive, optics and photometry, thermal, and physical.

Products Tested: Textiles and equipages/apparel products.

Standards/Test Principal standards are military, however, most textile and Methods: chemical standards and specifications of voluntary and govermmental basis are referenced, i.e., American Society for Testing and Materials (ASTM), federal specifications, etc.

Assessment Criteria/ Procedures:
Submission of Appropriate Documentation Independence (No Conflict-of-Interest)

Financial Stability

on-site Inspection

Staff Qualifications Requirements

Adequate Q.A. System

Sample Control/Integrity Requirements

Recordkeeping Requirements

Test Report Content/Format Requirements

Available Operational Manuals/Instructions

Periodic Random Re-audit of Facilities

Periodic Scheduled Re-audit of Facilities

Participation in a Proficiency Testing Program

Adequacy of Facilities \& Equipment

Equipment Maintenance/Calibration Requirements

other

Other Information: This program is applicable to the Laboratory Branch, Quality Assurance Division and all testing laboratories and contractors doing business on DPSC contracts. The QLI is furnished to all firms on the DPSC Clothing and Textiles' Bidders List to help contractors identify capable laboratories. Human resources, physical resources, and quality systems requirements are those essentially described in the American Society of Testing and Materials (ASTM) E548, "Practice for Preparation of Criteria for Use in the 
Accreditation

Terminology:

Compliance:

Authority:

Fees:

Accreditation Action Frequency:

Assessors:

Proficiency

Testing Program:
Evaluation of Testing and Inspection Bodies." Organizational and records requirements are different. Initial detailed documentation affords the basis for conditional or tentative approval.

Uses the term, "qualified," which means that the laboratories are found to be capable of performing the types of specification tests for which they are listed.

Voluntary for laboratory listing. Testing requirements, however, are mandatory for supplier of product through contractual requirements. Listing permits reduction in government verification tests.

No specific citation.

None.

Review of activity reports and response to complaints and other factors dictate frequency of laboratory review.

The agency maintains its own testing facility, and qualified personnel of that laboratory constitute principal assessors.

Samples with known results obtained in the areas deemed advisable as a reference sample procedure. Samples may also be tested concurrently by the qualified laboratory and the DPSC.

Appeal Procedure: Normal U.S. federal agency due process appeals mechanisms.

Publications:

A list of qualified laboratories is available.

Logo:

None.

No. of Labs:

Approximately 350 laboratories (as of June 30, 1989).

Availability of Accreditation:

Open to all U.S. laboratories.

List/Directory of Accredited Labs:

A "Qualified Laboratory List" is available.

Int'1 Recognition/

Agreements: None.

Other Recognition: None. 
Department/Agency: Envirommental Protection Agency (EPA)

Received: 11/90

Office of Drinking Water, WH-550D

401 M Street, SW

Washington, DC 20460

Phone: $\quad 202-382-3022$

FAX: $\quad 202-382-3762$

Program Title: Drinking water laboratory certification program.

Date Established: 1977.

Description: Provides for evaluation of laboratories which analyze public drinking water supplies for compliance purposes. Primacy states may certify local laboratories for testing drinking water in compliance with the Safe Drinking Water Act of 1974, as amended. Program covers EPA regional laboratories, principal state laboratories, and local laboratories in many states.

Fields of Testing: Biological, chemical, radiochemical.

Products Tested: Water.

Standards/Test EPA Drinking Water Regulations (40 CFR Parts 141, 142, and Methods:

Assessment

Criteria/

Procedures:

143), standards and protocols referenced by the Agency.

Submission of Appropriate Documentation

Independence (No conflict-of-Interest)

Financial stability

On-site Inspection

Staff Qualifications Requirements

Adequate Q.A. System

Sample control/Integrity Requirements

Recordkeeping Requirements

Test Report content/Format Requirements

Available Operational Manuals/Instructions

Periodic Random Re-audit of Facilities

Periodic Scheduled Re-audit of Facilities

Participation in a Proficiency Testing Program

Adequacy of Facilities \& Equipment

Equipment Maintenance/Calibration Requirements $\underline{x}$

other

Other Information: Criteria for accreditation include such factors as personnel training and experience, physical resources, analytical

capability, and quality control procedures. Documentation with application and conferences held on a pre-evaluation basis are used to explain what is expected by on-site review. On-site review will be followed by evaluation, report, and recommendations. Under this program, water system operators and/or state inspectors periodically collect water samples as specified in the Drinking Water Regulations and have them tested at a certified/approved laboratory. The frequency of the required monitoring depends on the contaminant, the water source (surface water or groundwater), and, in some instances, 
Aocreditation

Terminology:

Compliance:

Authority:

Fees:

Accreditation

Action Frequency:

Assessors:

Proficiency

Testing Program:

Appeal Procedure: Normal U.S. federal agency due process appeals mechanisms.

Publications:

Logo:

No. of Labs:

Availability of

Accreditation:

List/Directory of Accredited Labs: the size of the population served. Test results are reported to the state for appropriate action. EPA has established time frames and criteria for state enforcement actions.

Uses the terms, "approved," or "certified" which means that a laboratory has demonstrated to the EPA or the states that it is capable of performing the analytical measurements required in the drinking water program and obtaining accurate results.

Voluntary (but part of formal program).

Safe Drinking water Act, as amended. Under section 1413 of the amended act, a state has primary enforcement responsibility for public water systems and certifies local laboratories to test drinking water for compliance purposes.

No federal fees. States may charge fees for certifying local laboratories.

Annual performance evaluations samples must be analyzed.

on-site evaluations are scheduled every 3 years, unless an exception is granted by EPA.

Experienced laboratory personnel from EPA or the states.

Program requirements include satisfactory analysis of performance evaluation samples.

Laboratory certification manual, "Manual for the Certification of Laboratories Analyzing Drinking Water," is available from the above address.

None, though certified laboratories are issued certificates identifying areas of competency.

Eventual number could reach 2500 laboratories.

Subject to state regulations.

The National Registry of Laboratories Certified to Test

for Drinking Water Parameters, is available from the Association of State Drinking Water Administrators, 1911 North Fort Myer Drive, Arlington, VA 22209

Int'l Recognition/ Agreements:

Program could have unofficial international participation.

Other Recognition: None. 
Department/Agency: Enviromental Protection Agency (EPA)

Received: $8 / 90$

Office of Mobile Sources

Emission Control Technology Division

2565 Plymouth Road

Ann Arbor, MII 48105

Phone: $\quad 313-668-4299$

FAX: $\quad 313-668-4368$

Program Title: $\quad$ Retrofit Device Evaluation Program

Date Established: 1980.

Description: $\quad$ Recognizes independent laboratories as likely being capable of performing preliminary screening tests on vehicles for assessing the emission and fuel economy benefits of devices (including fuel additives). The preliminary testing is a screening mechanism only and therefore not used in lieu of EPA testing.

Fields of Testing: Chemical and mechanical.

Products Tested: Light duty on-highway transportation vehicles.

Standards/Test The evaluation and test protocols are provided for in 40 Methods: CFR Part 610, titled "Fuel Economy Retrofit Devices, Test Procedures and Evaluation Criteria" and in the EPA document "EPA Retrofit and Emission Control Device Evaluation Test policy," which may be obtained from the above address.

Assessment

criteria/

Procedures:
Submission of Appropriate Documentation

Independence (No Conflict-of-Interest)

Financial stability

on-site Inspection

Staff Qualifications Requirements

Adequate Q.A. System

Sample Control/Integrity Requirements

Recordkeeping Requirements

Test Report Content/Format Requirements

Available operational Manuals/Instructions

Periodic Random Re-audit of Facilities

Periodic Scheduled Re-audit of Facilities

Participation in a Proficiency Testing Program

Adequacy of Facilities \& Equipment

Equipment Maintenance/Calibration Requirements

other

other Information: The laboratory must have no financial interest in the outcome of testing other than the fees charged for the actual performance of the tests. The organization should be operating independently of any manufacturer of motor vehicles, engines, retrofit devices or fuel additives. Physical resources must be similar or equivalent to facilities and equipment in the EPA motor vehicle emissions laboratory. 
Accreditation

Terminology:

Compliance: Voluntary.

Authority:

Fees:

Accreditation

Action Frequency:

Assessors:

Proficiency

Testing Program: None.

Appeal Procedure: Normal U.S. federal agency due process appeals mechanisms.

Publications:

Logo:

NN. of Labs:

Availability of

Accreditation:

Uses the term, "recognized," which is defined as a test facility operated independently of any motor vehicle, motor vehicle engine, or retrofit device manufacturer and capable of performing retrofit device evaluation tests.

Section 511 of the Motor Vehicle Information and cost Savings Act, 15 USC 2011 et. seq.

None.

Test data is validated by correlation of test procedures, ambient control and the accuracy and precision of the measurement techniques and instrumentation.

EPA professional qualified staff.

See 40 CFR Part 610, titled "Fuel Economy Retrofit Devices, Test Procedures and Evaluation Criteria" and the EPA document "EPA Retrofit and Emission Control Device Evaluation Test policy," which may be obtained from the above address.

None.

N/A.

Open to all U.S. laboratories.

List/Directory of

Aocredited Labs: None.

Int'l Recognition/

Agreements: None.

Other Recognition: None. 
Department/Agency: Enviromental Protection Agency (EPA)

Received: $8 / 90$

Office of Air Quality Planning and Standards

Technical Support Division (MD-14)

Research Triangle Park, NC 27711

Phone: $\quad 919-541-1059$

FAX: $\quad 919-541-5663$

Program Title: Wood Stoves New Source Performance Standards Laboratory Accreditation

Date Established: 1988.

Description: In order to comply with the new source performance standards (Clean Air Act Section III), wood stoves manufacturers must use accredited laboratories to show (certify) that their stoves meet the air emission limits. Test conditions are specified in the Federal Register and laboratories undergo annual

performance proficiency tests. Stoves are subject to random audits.

Fields of Testing: Chemical, mechanical, thermal, air emissions/operations

Products Tested: Residential wood heaters

stardards/Test A list is contained in 40 CFR Part 60, subpart AAA and Methods:

Assessment

Criteria/

Procedures: Appendix A.

Submission of Appropriate Documentation

Independence (No Conflict-of-Interest)

Financial Stability

on-site Inspection

Staff Qualifications Requirements

Adequate Q.A. System

Sample Control/Integrity Requirements

Recordkeeping Requirements

Test Report Content/Format Requirements

Available Operational Manuals/Instructions

Periodic Random Re-audit of Facilities

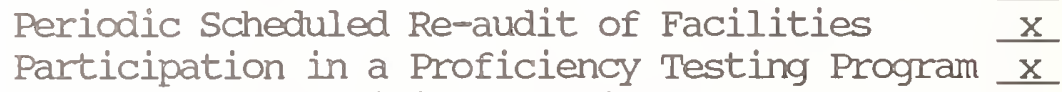

Adequacy of Facilities \& Equipment

Equipment Maintenance/Calibration Requirements $\frac{\mathrm{x}}{\underline{\mathrm{n}}}$

other

Other Information: Requirements are essentially comparable to those contained in the American Society of Testing and Materials (ASTM) E548, "Practice for Preparation of Criteria for Use in the Evaluation of Testing and Inspection Bodies." Program, however, has additional requirements for specific emission testing requirements.

Accrecitation Terminology:

Uses the term, "accredited," which is defined as a test facility operated independently of any motor vehicle, motor vehicle engine, or retrofit device manufacturer and capable of performing retrofit device evaluation tests. 
Compliance: Mandatory

Authority: Clean Air Act Section III and 40 CFR Part 60, subpart AAA and Appendix A.

Fees: None.

Accreditation

Action Frequency: Annual accreditation is required.

Assessors: $\quad$ EPA Technical Support Division and Stationary Source

Compliance Division of the Office of Air Quality Planning and Standards.

Proficiency

Testing Program: Proficiency testing is required annually.

Appeal Procedure: Normal U.S. federal agency due process appeals mechanisms.

Publications: See 40 CFR Part 610, titled "Fuel Economy Retrofit Devices, Test Procedures and Evaluation Criteria" and the EPA

document "EPA Retrofit and Emission Control Device Evaluation Test Policy," which may be obtained from the above address.

Logo: Yes, for the stove.

No. of Labs: Nine laboratories as of July 1990.

Availability of Accreditation:

open to all U.S. laboratories.

List/Directory of Yes, List of Accredited NSPS Woodstoves Laboratories is Accredited Labs: available from above address.

Int'1 Recognition/

Agreements: None.

Other Recognition: Required throughout the United States. 
Department/Agency: Federal Communications Commission (FCC)

Office of Engineering \& Technology

Authorization \& Evaluation Division

Chief, Equipment Authorization Branch

7435 Dakland Mills Road

Columbia, MD 21046

Fhone:

$301-725-1585$

Program Title: Description of Measurement Facilities.

Date Established: 1975.

Description: Laboratories making measurements of devices that are included in applications for FCC equipment (radio frequency emitting devices) authorization provide a description of their facilities. The limited descriptive information does not require FCC approval and no inspections of the sites are required. However, the FCC may reject measurement data from facilities which file incomplete descriptions or show deficiencies.

Fields of Testing: Electrical.

Products Tested: Radio frequency emitting devices.

Standards/Test As required by the device being tested. May employ FCC Methods: and/or referenced voluntary consensus standards.

Assessment criteria/ Procedures:
Submission of Appropriate Documentation Independence (No Conflict-of-Interest) Financial stability on-site Inspection Staff Qualifications Requirements Adequate Q.A. System Sample Control/Integrity Requirements Recordkeeping Requirements Test Report content/Format Requirements Available Operational Manuals/Instructions Periodic Random Re-audit of Facilities Periodic Scheduled Re-listing of Facilities Participation in a Proficiency Testing Program Adequacy of Facilities \& Equipment Equipment Maintenance/Calibration Requirements other site qualification test data

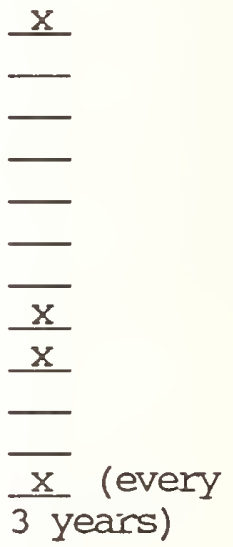

$\frac{x}{x}$ $\frac{x}{x}$ $\mathrm{x}$

Other Information: Emphasis is placed on physical resources which constitute principal FCC concerns; however, site situation and IISN data is required. Description filing reviewed for completeness and technical capability of facility.

Accreditation Terminology:

No specific terminology used. 
Compliance:

Voluntary for testing facilities. Mandatory for applicants for devices subject to certification and notification under 47 CFR Parts 15 and 18.

Authority:

Fees:

Accreditation Action Frequency:

Assessors:

Proficiency Testing Program:
47 CFR Part 2.948, Description of Measurement Facilities. None.

Information shall be kept current at all times. At least every 3 years, the organization filing the data shall advise that the data on file is current.

The professional staff of the FCC laboratory constitute principal assessors.

Although no formal program exists, the retest of identical units at FCC facility acts as a proficiency sample random method.

Appeal Procedure: Normal U.S. federal agency due process appeals mechanisms.

Publications:

47 CFR 2.948 and OET Bulletin 55.

Iogo:

None.

No. of Iabs:

Approximately 300 laboratories as of March 1990.

Availability of Aocreditation:

Open to all laboratories.

List/Directory of FCC maintains a list of parties who have filed the required Accredited Labs: information.

Int'l Recognition' Agreements:
None. 
Department/Agency: Department of Health \& Human Services (HHS)

Received: 5/90

Alcohol, Drug Abuse, \& Mental Health Administration (ADAMHA)

National Institute on Drug Abuse

Division of Applied Research, Drug Testing Section

Room 9A-53

5600 Fishers Lane

Rockville, MD 20857

Phone: $\quad 301-443-6014$

FAX: $\quad 301-443-2636$

Program Title: National Laboratory Certification Program (NLCP) .

Date Established: April 11, 1988.

Description: This program establishes appropriate standards and procedures

for periodic review of laboratories and criteria for laboratory certification for urine drug testing for federal agencies. The program certifies laboratories to perform forensic urine drug testing. Methodology includes immunoassay screen followed by a gas chromatography/mass spectrometry confimation. cut-off levels established for marijuana metabolites, cocaine metabolites, opiates, phencyclidine, and amphetamines.

Fields of Testing: Chemical, forensic toxicology.

Products Tested: Urine samples for drugs of abuse, specifically, marijuana, cocaine, opiates, PCP and amphetamines.

Standards/Test Methods:

Assessment Criteria/ Procedures:
A list of standards/test methods for which laboratories may be accredited may be obtained by requesting the Mandatory Guidelines From NIDA.

Submission of Appropriate Documentation Independence (No conflict-of-Interest)

Financial stability

on-site Inspection

Staff Qualifications Requirements

Adequate Q.A. System

Sample control/Integrity Requirements Recordkeeping Requirements

Test Report content/Format Requirements Available operational Manuals/Instructions Periodic Random Re-audit of Facilities Periodic Scheduled Re-audit of Facilities Participation in a Performance Testing Program Adequacy of Facilities \& Equipment Equipment Maintenance/Calibration Requirements other Requirements - Security Requirements

- Availability of personnel to testify

$\frac{\frac{x}{\frac{x}{x}}}{\frac{x}{\frac{x}{x}}} \frac{\frac{x}{x}}{\frac{x}{x}} \frac{\frac{x}{x}}{\frac{x}{x}} \frac{\frac{x}{x}}{\frac{x}{x}}$


Other Information: Requirements are in accordance with ASTM E 548, though the program includes more detailed security and sample chain of custody requirements in the accreditation procedures. Procedures are comparable to DOD's drug testing program for military personnel.

Aocreditation Terminology:

Campliance:

Authority:

Fees:

Accreditation

Action Frequency: Twice a year.

Assessors: NCLP staff.

Proficiency

Testing Program: Procedures spelled out in 53 FR 11986, April 11, 1988.

Appeal Procedure: Normal U.S. federal agency due process appeals mechanisms. In addition, an appeal may be made to the Secretary HHS. Appeal procedures are described in Mandatory Guidelines.

Publications: Executive order 125654 and 53 FR 11986, April 11, 1988, Mandatory Guidelines for Federal Workplace Drug Testing Programs.

Logo: None.

No. of Labs: Approximately 48 laboratories as of $3 / 90$.

Availability of open to all domestic private, state and federal laboratories. Accreditation: Also open to all foreign private and govermment laboratories.

List/Directory of Accredited Labs:

A list is published in the Federal Register every other month.
Int'1 Recognition/ Agreements:

Other

Recognition:
None.

Program is recognized by all federal agencies, DOT and NRC regulated industries, and HCFA (CLIA 1988). 
Department/Agency: Department of Health \& Human Services (HHS)

Food \& Drug Administration (FDA)

Bioresearch Program, (HFC-30)

Room 15A-03 Parklawn Bldg.

5600 Fishers Lane

Rockville, MD 20857

Phone: $\quad 301-443-2390$

FAX: $\quad 301-443-3496$

Program Title: Toxicology laboratory monitoring program.

Date Established: June 21, 1979.

Description: Program seeks to assure the quality and integrity of the safety data collected on drugs, food and feed additives, human biological products and medical devices in order to support regulatory decision making. FDA inspects nonclinical laboratories to determine whether they are following good laboratory practices (GLP).

Fields of Testing: Biological/toxicological.

Products Tested: Human and animal drugs, food and feed additives, human biological products and medical devices, electronic products that emit radiation.

Standands/Test Methods:

Any and all appropriate rules and regulations of the FDA; and in particular, those contained in 21 CFR Part 58.

Assessment Criteria/ Procedures:

Submission of Appropriate Documentation Independence (No Conflict-of-Interest)

Financial stability

On-site Inspection

Staff Qualifications Requirements

Adequate Q.A. System

Sample Control/Integrity Requirements

Recordkeeping Requirements

Test Report content/Format Requirements

Available Operational Manuals/Instructions

Periodic Random Re-audit of Facilities

Periodic Scheduled Re-audit of Facilities

Participation in a Proficiency Testing Program

Adequacy of Facilities \& Equipment

Equipment Maintenance/Calibration Requirements

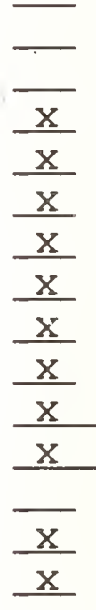

Other

Other Information: Laboratory documentation is reviewed and an on-site examination is conducted to evaluate the laboratory's capability. Requirements are comparable to those contained in the American Society of Testing and Materials (ASTM) E548, "Practice for Preparation of Criteria for Use in the Evaluation of Testing and Inspection Bodies," and European Norm 45002. 
Terminology:

Compliance:

Authority:

Fees:

Inspection Action Frequency:

Assessors:

Proficiency

Testing Program:

Appeal Procedure: Normal U.S. federal agency due process appeals mechanisms are spelled out in regulations.

Publications:

Logo:

No. of Labs:

Availability of Coverage:

List/Directory of Inspected Labs:

No specific terminology used other than "complies with GLP regulations." Laboratories not complying with GLP regulations are referred to as "disqualified."

Mandatory for laboratories conducting tests on FDA regulated products.

21 CFR Part 58 (published in the Federal Register on December 22, 1978), in accordance with the Federal Food, Drug and cosmetic Act and other applicable laws.

None.

A testing facility shall permit an authorized employee of the Food and Drug Administration, at reasonable times and in a reasonable manner, to inspect the facility and to inspect (and in the case of records also to copy) all records and specimens which FDA requires the facility to maintain. Routine inspections of domestic laboratories are made biennially. Laboratories requiring data audit inspections are identified by EPA and scheduled when necessary.

Qualified FDA field inspectors.

None currently employed.

21 CFR Part 58 - Good Laboratory Practice for Nonclinical Laboratory Studies, documents describing program and procedures are available. Copies of individual inspection reports may be obtained as a Freedom of Information request.

None.

Approximately 400 laboratories inspected as of March 6, 1990.

Open to all U.S. private sector, federal and state government laboratories, as well as foreign private sector and government laboratories.

FDA maintains a list of toxicology laboratories that have been inspected for compliance with the GLP's.

Int'l Recognition/ Agreements have been established with Canada, Switzerland, Agreements: Germany, the Netherlands, France, Sweden, the U.K., Japan, and Italy, and the Organization for Economic cooperation and Development (OECD) .

Other Recognition: Cooperates with EPA, USDA, the Department of the Army, and the CPSC. 
Department/Agency: Department of Health \& Human Services (HHS)

Received: $6 / 90$

Food \& Drug Administration (FDA)

Center for Food Safety and Applied Nutrition

Principal Milk Laboratory Evaluation officer

Lab. QA Branch

10 West 35th Street

Chicago, IL 60616-3799

Phone:

$312-353-1025$

Program Title: Evaluation of milk laboratories.

Date Established: 1951.

Description:

Evaluates and endorses laboratory sample collection surveillance procedures to provide a national base for the uniform collection and examination of milk.

Fields of Testing: Biological and chemical.

Products Tested: Milk and milk products.

Standards/Test

Methods:

Test procedures are described in "Standard Methods for the Examination of Dairy Products," and "Official Methods of Analysis of the Association of Official Analytical Chemists," FDA Forms FDA 2400-2400j, criteria for accreditation defined in "Evaluation of Milk Laboratories."

Assessment Criteria/ Procedures:
Submission of Appropriate Documentation Independence (No Conflict-of-Interest) Financial Stability On-site Inspection

Staff Qualifications Requirements Adequate Q.A. System Sample Control/Integrity Requirements Recordkeeping Requirements Test Report Content/Format Requirements Available operational Manuals/Instructions Periodic Random Re-audit of Facilities Periodic Scheduled Re-audit of Facilities Participation in a Proficiency Testing Program $\mathrm{x}$ Adequacy of Facilities \& Equipment $\frac{x}{x}$ Equipment Maintenance/Calibration Requirements $\frac{\mathrm{x}}{\mathrm{x}}$ other

Other Information: Individual laboratories are accredited for specific test procedures and official testing is done only at accredited laboratories. Criteria include adequate physical resources and qualified human resources determined by on-site evaluation, and technical skills of analysts determined by proficiency testing. Human and quality system requirements exceed the suggested guidelines in the American Society of Testing and Materials (ASTM) E548, "Practice for Preparation of Criteria for Use in the Evaluation of Testing and Inspection Bodies." on-site evaluation, including review of each analyst for all procedures. 
Accreditation

Terminology:

compliance:

Authority:

Fees:

Accreditation Action Frequency:

Assessors:

Proficiency

Testing Program:

Appeal Procedure:

Publications:

Logo:

No. of Labs:

Availability of Accreditation:

List/Directory of Accredited Labs:
Uses the term, "accredited," meaning a milk laboratory certified as to performance of analyses by an appropriate agency.

Voluntary for state, commercial and industry laboratories. Established by FDA, the states and National Conference of Interstate Milk Shippers (NCIMS). NCIMS is an alliance of federal USDA and state regulatory agencies controlling the interstate movement of grade A milk and milk products. The program is voluntary for states.

Food, Drug and Cosmetic Act; Public Health Service Act; memorandum of understanding between FDA and NCIMS.

None on federal level.

Triennial on-site evaluation by FDA and biennial on-site review in state programs with at least annual split sample analysis. Additional monitoring as required.

Experienced, trained laboratory personnel with qualifying education.

Split sample analysis is a mandatory program requirement.

Normal U.S. federal agency due process appeals mechanisms.

"Evaluation of Milk Laboratories," "Recommendations of the United States Public Health Service/Food and Drug Administration;" "Sanitation compliance and Enforcement Ratings of Interstate Milk Shippers" (a quarterly listing of all accredited laboratories) are available.

None.

681 laboratories as of April 1990.

open to state, commercial and industry laboratories.

"Sanitation Compliance and Enforcement Ratings of Interstate Milk Shippers" (a quarterly listing of all accredited laboratories) is available from the above address.

Int'1 Recognition/

Agreements: None.

other

Recognition:
States participating in the National conference of Interstate Milk Shippers (NCIMS). 
Department/Agency: Department of Health \& Human Services (HHS)

Received: $5 / 90$

Health Care Financing Administration (HCFA)

Health Standards and Quality Bureau

2D3 Meadows East Bldg.

6325 Security Blvd.

Baltimore, MD 21207

Phone: $\quad 301-966-6801$

FAX: $\quad 301-966-6730$

Program Title: Clinical Laboratories Improvement Act of 1967 (CIIA '67) \&

Medicare. Requirements under the CLIA '88 being developed.

Date Established: CIIA - 1969; Medicare - 1966. Requirements under CIIA '88 are under development.

Description: $\quad$ CIIA is a licensure program required for laboratories in interstate commerce. Laboratories seeking payment under Medicare or Medicaid must also be certified for participation.

Fields of Testing: Biological, clinical.

Products Tested: Human specimens.

Standards/Test Laboratories are licensed or certified by specialty or Methods: subspecialties.

Assessment

Submission of Appropriate Documentation

Criteria/

Independence (No Conflict-of-Interest)

Procedures:

Financial stability

On-site Inspection

Staff Qualifications Requirements

Adequate Q.A. System

Sample control/Integrity Requirements

Recordkeeping Requirements

Test Report content/Format Requirements

Available operational Manuals/Instructions

Periodic Random Re-audit of Facilities

Periodic Scheduled Re-audit of Facilities $\frac{}{\mathrm{x}}$

Participation in a Proficiency Testing Program $\mathrm{x}$

Adequacy of Facilities \& Equipment

Equipment Maintenance/Calibration Requirements $\frac{\mathrm{x}}{\mathrm{x}}$

other

Other Information: Requirements under Medicare and CLIA '67 are much more specific the suggested guidelines offered in the American Society of Testing and Materials (ASTM) E548, "Practice for Preparation of Criteria for Use in the Evaluation of Testing and Inspection Bodies."

HCFA now has the responsibility for implementing the CLTA '88 for the certification of all entities that test human specimens. Proposed rules are being developed to establish federal health and safety requirements for the certification of laboratories under the CIIA '88. Among CITA '88 requirements to be developed are standards for collection of fees to cover all program costs of administering the CIIA 


\section{Accreditation \\ Terminology:}

compliance:

Authority:

Fees:

Aocreditation

Action Frequency:

Assessors:

Proficiency

Testing Program:

Appeal Procedure:

Publications:

Logo:

No. of Labs:

Availability of

Accreditation:

List/Directory of Accredited Labs: program as well as establishing the criteria to be used for the recognition of laboratory accreditation and state licensure programs. CLIA '88 expands HCFA's universe of regulated laboratories from 12,000 laboratories to a potential of 300,000 to 600,00 laboratories.

Uses the term, "approved clinical laboratory," meaning a laboratory licensed under the CLIA or approved under medicare regulations. Also uses the term "licensed," meaning a laboratory approved under the CLIA to test specimens shipped in interstate commerce.

Voluntary for laboratories that serve as cooperating participants. Mandatory for laboratories engaged in interstate conmerce or seeking reimbursement under medicare/medicaid.

Clinical Laboratories Improvement Act of 1967. Regulations may be found under 42 CFR Part 74 Social Security Act, and Medicare regulations under 42 CFR Subpart M.

None.

Licenses are issued annually. Medicare approval letters are sent to laboratories following each inspection to reflect laboratory's certification status.

State survey agencies conduct inspections and HCFA regional offices certify state agency findings.

On-site proficiency testing may be employed from time-to-time. Requirements are contained in $42 \mathrm{CFR}$ 405.1314(a) and 42 CFR Part 74.40-43.

Normal U.S. federal agency due process appeals mechanisms.

Clinical Laboratories Improvement Act of 1967. Regulations may be found under 42 CFR Part 74 Social Security Act, and Medicare regulations under 42 CFR subpart M.

Department of Health and Human Services Logo.

Approximately 2871 laboratories licensed to test interstate specimens as of 3/15/90 and 4811 laboratories approved for medicare participation as of 12/30/89.

Open to all U.S. laboratories.

There is an alphabetic Listing of Medicare Approved Independent Laboratories available from the above address.
Int'1 Reoognition/ Agreements:

Other

Recognition:
Unofficial international participation is involved.

State licensure laws frequently reference federal laboratory regulations and require compliance with federal standards. New York State program has been recognized under CLIA '67. 
Received: $6 / 90$

Department/Agency: Department of Housing \& Urban Development (HUD)

Federal Housing Administration (FHA)

Materials Engineer, Office of Architecture \& Engineering

Materials Acceptance Division

Washington, DC 20410

Phone: $\quad 202-708-1029$

Program Title: Technical suitability of building products program.

Date Established: 1964.

Description: Accredits thind-party organizations which validate manufacturers' certifications that certain building materials meet applicable requirements.

Fields of Testing: Mechanical and chemical.

Products Tested: Building products including: carpet, grade marking of lumber, aluminum windows and doors, grade marking of plywood, pressure treated lumber, wood flush doors, wood windows, wood sliding patio doors, glued plywood flooring, textured plywood siding, 1-1/8" plywood flooring, particleboard stair treads, plastic plumbing fixtures, insulating glass, and solid fuel burning devices.

Standards/Test Methods:

Assessment Criteria/ Procedures:
Applicable HUD Use of Materials bulletins and referenced testing procedures, standards or specifications.

Submission of Appropriate Documentation Independence (No Conflict-of-Interest)

Financial stability

on-site Inspection

Staff qualifications Requirements

Adequate Q.A. System

Sample Control/Integrity Requirements

Recordkeeping Requirements

Test Report Content/Format Requirements

Available Operational Manuals/Instructions

Periodic Random Re-audit of Facilities

Periodic Scheduled Re-audit of Facilities

Participation in a Proficiency Testing Program

Adequacy of Facilities \& Equipment

Equipment Maintenance/Calibration Requirements

Other

Other Information: Human resources, physical resources, and quality systems requirements essentially follow the guidelines of the American Society of Testing and Materials (ASTM) E548, "Practice for Preparation of Criteria for Use in the Evaluation of Testing and Inspection Bodies."

Formal documentation is required of all laboratories. Documentation consists of product test qualifications for both personnel and facilities which is verified by on-site reviews in all laboratories. 
Accreditation Terminology:

campliance:

Authority:

Fees:

Accreditation Action Frequency:

Assessors:

Proficiency

Testing Program:

Accrediting

Authority:

Appeal Procedure: an

Publications:

Logo:

No. of Labs:
Uses the term, "accepted," meaning an administrator (organization) which is capable of conducting a certification program through its organization, staff and facilities and have a reputation for adhering to high ethical standards.

Voluntary. Mandatory for manufacturers if involved in HUD programs.

24 CFR Part 200, Administrator Qualifications and Procedures for HUD Building Products Certification Programs, dated September 20, 1979. Organizations acceptable to HUD are authorized as administrators of the program. Administrators must accredit the laboratories they use. (Carpet administrators must use the NIST NVIAP accredited laboratories.)

Manufacturers laboratory fees for approval are included in the participation charges of the administrator, fees may be collected from commercial laboratories at the discretion of the administrator.

Documentation must be kept current. Reviews are scheduled on a 1 or 2 year cycle with more frequent reviews possible if deemed advisable by the administrator.

Administrator's staff or consultants.

None, however, appropriate round-robin procedures for commercial may be employed by administrators.

Approved administrators.

A procedure is contained in each administrator's program and additional appeal to HUD officials is possible.

The administrators must provide a directory of certified products in which the names of both participating manufacturers and approved laboratories appear.

The accredited laboratories do not employ a program logo. An administrator's logo appears on certified products.

No exact count is available. There are approximately 30 administrators which accredit from one to 40 laboratories each.

Int'l Recognition/

Agreements: None currently. 

Department/Agency: Department of Interior
Office of Surface Mining Reclamation \& Enforcement (OSM)
Division of Technical Services
1951 Constitution Ave., NW
Washington, DC 20240

Received: 6/90

Phone: $\quad 202-343-1507$

FAX: $\quad 202-898-1291$

Program Title: Small Operator Assistance Program (SOAP) .

Date Fstablished: 1979.

Description: Laboratories, qualified as part of the federal procurement process, prepare a determination of probable hydrologic consequences and a statement of results of test borings or core samplings for eligible small coal operators, producing less than 100,000 tons of coal annually. The information is used for the operator's coal mine permit application.

Fields of Testing: Chemical, thermal, water quality, hydrology, overburden testing.

Products Tested: Soil, rock, water.

Standards/Test There is no list of standards/test methods for which Methods: laboratories are accredited. General requirements may be found in $30 \mathrm{CFR} 795.10$.

Assessment Criteria/ Procedures:
Submission of Appropriate Documentation Independence (No Conflict-of-Interest)

Financial stability

on-site Inspection

Staff Qualifications Requirements

Adequate Q.A. System

Sample Control/Integrity Requirements

Recordkeeping Requirements

Test Report content/Format Requirements

Available Operational Manuals/Instructions

Periodic Random Re-audit of Facilities

Periodic Scheduled Re-audit of Facilities

Participation in a Proficiency Testing Program

Adequacy of Facilities \& Equipment

Equipment Maintenance/Calibration Requirements $\frac{\mathrm{x}}{\underline{\mathrm{x}}}$ Other

Other Information: NOTE: In the past, OSM qualified laboratories separate from the procurement process. This practice ended in 1983 when regulations for the SOAP were revised. Program uses some, but not all of the criteria of the American Society of Testing and Materials (ASTM) E548, "Practice for Preparation of Criteria for Use in the Evaluation of Testing and Inspection Bodies." 
Accreditation

Terminology:

Compliance:

Authority:

Fees:

Accreditation

Action Frequency

Assessors:

Proficiency

Testing Program: No.

Appeal Procedure: Normal U.S. federal agency due process appeals mechanisms.

Publications: $\quad 30$ CFR Part 795.

Logo:

No. of Labs:

Availability of Aocreditation:

Uses the term, "qualified," meaning a designated public agency, private firm, institution, or analytical laboratory which can prepare the required determination of probable hydrologic consequences or statement of results of test borings or core samplings.

Voluntary.

Sec. 507 (c) of P.L. 95-87, 30 CFR Part 795.

N/A.

N/A.

Technical proposals are evaluated by professional staff.

List/Directory of Accredited Labs:

Int'l Recognition/

Agreements:

None.

One laboratory as of June 1990.

Program is open to all U.S. state, federal and private sector laboratories.

N/A.

None.

Other

Recognition: None. 
Department/Agency: Department of Iabor (DOL)

Received: $4 / 90$

Mine Safety \& Health Administration (MSHA)

Approval \& Certification Center (A\&CC)

RRI, Box 251

Industrial Park Road

Triadelphia, WV 26059

Phone:

Date Established:

Description:
(304) -547-0400 FTS: 723-1501

1952 by the Federal Coal Mine Safety Act.

Accreditation of inspection/test laboratories as a function of manufacturer quality control maintenance for component parts made and assembled for MSHA approval or certification.

Fields of Testing: Electrical, mechanical.

Products Tested: Electrical machinery, equipment, supplies and appliances.

Standards/Test

Methods:

Assessment

Criteria/

Procedures:
Standards, test methods, examinations and procedures are contained in Title 30 of the CFR. There are also MSHA/A\&CC procedural requirements for products requiring approval and certification.

Submission of Appropriate Documentation Independence (No Conflict-of-Interest)

Financial stability

On-site Inspection

Staff Qualifications Requirements

Adequate Q.A. System

Sample control/Integrity Requirements

Recordkeeping Requirements

Test Report content/Format Requirements

Available Operational Manuals/Instructions

Periodic Random Re-audit of Facilities

Periodic Scheduled Re-audit of Facilities

Participation in a Proficiency Testing Program

Adequacy of Facilities \& Equipment

Equipment Maintenance/Calibration Requirements

other Periodic Product Audits

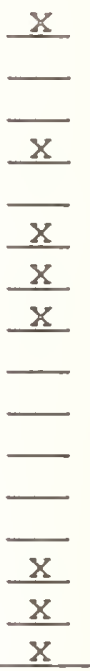

Other Information: Since this program provides ongoing support for continued compliance of products with certification and approval requirements, it addresses primarily the organizational, quality systems, and physical resources requirements such as those covered in the guidelines of the American Society of Testing and Materials (ASTM) E548, "Practice for Preparation of Criteria for Use in the Evaluation of Testing and

Inspection Bodies." A detailed quality characteristics inspection and test application is required with detailed inspection and test procedures, together with methods of test, instrumentation, test equipment and referenced procedures including sampling, plans. The application is verified through product testing and on-site review as required. 
Accreditation

Terminology:

Compliance:

Authority:

Fees:

Accreditation

Action Frequency:

Assessors:

Proficiency

Testing Program:

Appeal Procedure:

Publications:

Logo:

No. of Labs:

Availability of Aocreditation:
No specific terminology.

Voluntary approval and certification programs, with inspection/test accreditation mandatory where they apply to such products.

Title 30 of the CFR.

Fees are included in product approval and certification charges.

Accreditation is a function of product monitoring and may be reviewed by product changes and/or retest at MSHA, A\&CC. Inspection/test is essential during period of certification and approval of products.

All assessmeints of inspection/test adequacy, in laboratory and on-site are performed by the professional staff of the MSHA, A\&CC.

MSHA reserves the right to retest products or to witness product testing at the test facility.

Normal U.S. federal agency due process appeals mechanisms.

Basic publication is Title 30 of the CFR with each part type having its own instructions, application forms and submission/testing/evaluation details. General material for approval of mining products from review of analytical location center and other circulars, lists of qualified/approved products, manufacturers.

MSHA Logo for products, none for accredited inspection/test facility.

Estimated at over 250 laboratories.

open to all U.S. laboratories. MSHA will accept product testing conducted outside the United States where such acceptance is specifically required by international agreement.

List/Directory of Accredited Labs:

Int'l Recognition/ Agreements:

None.

Since mine safety products are both exported and imported, the program has international recognition in this product area.

Other

Recognition:

Generally accepted by state authorities. 
Department/Agency: Department of Labor (DOL)

Received: $4 / 90$

Mine Safety \& Health Administration (MSHA)

Approval \& Certification Center (A\&CC)

RRI, Box 251

Industrial Park Road

Triadelphia, WV 26059

Phone:

(304) $-547-0400$ FTS: 723-1501

Date Established: 1976.

Program Title: Testing and Evaluation of Illumination Systems.

Description: Requires site evaluation to determine if light laboratory meets the criteria as a simulated working place. Requirements have been established for the laboratory and for the measurement procedures. MSHA reserves the right to witness, retest and is the approval issuer.

Fields of Testing: Electrical, mechanical.

Products Tested: Illumination equipment for mines.

Standards/Test

Methods:

Standards, test methods, examinations and procedures are contained in 30 CFR Part 75.1719. There are also MSHA/A\&CC procedural requirements for products requiring approval and certification.

Assessment

Criteria/

Procedures:
Submission of Appropriate Documentation

Independence (No Conflict-of-Interest)

Financial stability

On-site Inspection

Staff Qualifications Requirements

Adequate Q.A. System

Sample Control/Integrity Requirements

Recordkeeping Requirements

Test Report content/Format Requirements

Available operational Manuals/Instructions

Periodic Random Re-audit of Facilities

Periodic Scheduled Re-audit of Facilities

Participation in a Proficiency Testing Program

- MSHA reserves the right to retest products at its own facility

Adequacy of Facilities \& Equipment Equipment Maintenance/Calibration Requirements Other

other Information: This program addresses primarily equipment maintenance, calibration, and testing procedures; quality control; and physical resources requirements, such as those covered in the guidelines of the American Society of Testing and Materials (ASTM) E548, "Practice for Preparation of Criteria for Use in the Evaluation of Testing and Inspection Bodies." MSHA reserves the right to witness testing at the facility. 
Accreditation

Terminology:

Campliance:

Fees:

Accreditation

Action Frequency:

Assessors:

Proficiency

Testing Program:

Appeal Procedure:

Publications:

Logo:

No. of Labs:

Availability of Aocreditation:
Aurthority:

No specific terminology.

Voluntary for laboratories, except those wishing to test the compliance of illumination products to MSHA requirements.

30 CFR 75 and 41 FR 14108, April 1, 1976.

Fees are assessed by MSHA based on costs involved.

Accreditation is a function of product monitoring and may be reviewed by product changes and/or retest at MSHA, A\&CC.

Inspection/test is essential during period of certification and approval of products.

All assessments of inspection/test adequacy, in laboratory and on-site are performed by the professional staff of the MSHA, A\&CC.

MSHA reserves the right to retest products or to witness product testing at the test facility.

Normal U.S. federal agency due process appeals mechanisms.

"Handbook of Underground Coal Mine Illumination Requirements" 30 CFR 75.1719, and 41 FR 14108, April 1, 1976.

Letter of acceptance and MSHA marking for products, none for accredited facility.

Not available.

Open to all U.S. laboratories. MSHA will accept product testing conducted outside the United States where such acceptance is specifically required by international agreement.

List/Directory of Accredited Labs: None.

Int'l Recognition/ Since mine safety products are both exported and imported, the Agreements:

program has international recognition.

Other

Recognition: Generally accepted by state authorities. 
Department/Agency: Department of Labor (DOL)

Received: $4 / 90$

Mine Safety \& Health Administration (MSHA)

Approval \& Certification Center (A\&CC)

RRI, Box 251

Industrial Park Road

Triadelphia, WV 26059

Phone:

(304) $-547-0400$ FTS: 723-1501

Date Established: 1988.

Program Title: Testing by Applicant or Third Party.

Description: Requires testing of specific products at the manufacturer or at a third-party laboratory. MSHA reserves the right to witness tests, retest, and is the approval issuing authority. subparts will be issued by product line.

Fields of Testing: Electrical, mechanical.

Products Tested: Mining equipment, including brattice cloth, ventilation tubing, battery assemblies, multiple shot blasting units. other products may be added in the future.

Standards/Test Methods:

Assessment criteria/ Procedures:
Standards, test methods, examinations and procedures are contained in 30 CFR Part 7 or 53 FR 23486, June 22, 1988.

Submission of Appropriate Documentation Independence (No conflict-of-Interest) Financial Stability On-site Inspection Staff qualifications Requirements Adequate Q.A. System Sample control/Integrity Requirements Recordkeeping Requirements Test Report Content/Format Requirements Available Operational Manuals/Instructions Periodic Random Re-audit of Facilities Periodic Scheduled Re-audit of Facilities Participation in a Proficiency Testing Program - MSHA reserves the right to retest products $\underline{x}$ Adequacy of Facilities \& Equipment Equipment Maintenance/Calibration Requirements $\frac{\mathrm{x}}{\underline{\mathrm{x}}}$ other

Other Information: This program addresses primarily equipment maintenance, calibration, testing procecures, and quality control requirements such as those covered in the guidelines of the American Society of Testing and Materials (ASTM) E548, "Practice for Preparation of Criteria for Use in the Evaluation of Testing and Inspection Bodies." MSHA reserves the right to witness testing at the facility.

Accreditation Terminology: No specific terminology. 
Compliance:

Authority:

Fees:

Accreditation Action Frequency:

Assessors:

Proficiency Testing Program:

Appeal Procodure:

Publications:

Logo:

№. of Labs:

Availability of Accreditation:

List/Directory of Accredited Labs:

Int'l Recognition/ Agreements:

Other Recognition:
Voluntary for laboratories, except those wishing to test the compliance of products listed above to MSHA requirements.

10 USC 957, 30 CFR 7.

Fees for product approval are determined by MSHA. No fees specifically assessed to the test facility.

Acceptance of test results is a part of the product approval process. Product approvals may be reviewed by and products retested as required.

All assessments of inspection/test adequacy, in laboratory and on-site are performed by the professional staff of the MSHA, A\&CC.

MSHA reserves the right to retest products or to witness product testing at the test facility.

Normal U.S. federal agency due process appeals mechanisms.

30 CFR 7; FR, June 22, 1988; and guidance.

Letter of acceptance and MSHA marking for products, none for test facility.

Not available.

Open to any laboratory chosen by the applicant for product approval.

None.

Since mine safety products are both exported and imported, the program has international recognition.

Generally accepted by state authorities. 
Department/Agency: Department of Labor (DOL)

Occupational Safety Health Administration (OSHA)

Office of Variance Determination

NRTL Program, Room 3653

200 Constitution Avenue, NW

Washington, DC 20210

Phone: $\quad 202-523-8131$

FAX: $\quad 202-523-5046$

Program Title: Nationally Recognized Testing Laboratories (NRTL) Program.

Date Established: June 13, 1988.

Description: The applicant for OSHA recognition as an NRTL shall have administrative and technical capability to conduct product testing activities and report on the results, to approve products (product certification), to inspect factory production runs for product evaluation, and to conduct field inspections to assure proper use of its identifying mark or label on these products.

Fields of Testing: Electrical, fire protection.

Products Tested: Electrical and related products used in the workplace.

Standards/Test Methods:
Assessment Criterial Procedures:
A list of standards/test methods for which laboratories may be accredited is contained in 29 CFR Part 1910, OSHA General Industry Standards.

Submission of Appropriate Documentation Independence (No Conflict-of-Interest)

Financial Stability

on-site Inspection

Staff Qualifications Requirements

Adequate Q.A. System

Sample Control/Integrity Requirements

Recordkeeping Requirements

Test Report content/Format Requirements

Available Operational Manuals/Instructions

Periodic Random Re-audit of Facilities

Periodic Scheduled Re-audit of Facilities

Participation in a Proficiency Testing Program

Adequacy of Facilities \& Equipment

Equipment Maintenance/Calibration Requirements $\mathrm{x}$

other

Other Information: The requirements are compatible with those contained in the American Society of Testing and Materials (ASTM) E548, "Practice for Preparation of Criteria for Use in the Evaluation of Testing and Inspection Bodies," and appropriate international standards/guides. Laboratories, which are accredited, however must also have a product approval (certification) function. 
Accreditation

Terminology:

Campliance:

Authority:

Fees:

Accreditation

Action Frequency

Assessors:

Proficiency

Testing Program: None available.

Appeal Procedure: Normal U.S. federal agency due process appeals mechanisms. In addition each NRTL must have an acceptable appeals process.

Publications: $\quad$ OSHA standards and Federal Register notices.

Logo:

No. of Labs:

Availability of Accreditation:
Uses the term, "nationally recognized," meaning an organization that is recognized by OSHA and tests for safety and lists, labels, or accepts equipment or materials that meet specific criteria.

Voluntary as to participation by the laboratory.

29 CFR Part 1910.7.

No laboratory fees are required.
Every 5 years.

Qualified OSHA and Mine Safety and Health Administration (MSHA) staff.

Yes, there is a logo. In addition NRTL's must apply their own mark to approved products.

Five laboratories as of March 6, 1990.

open to all U.S. laboratories and to foreign private sector laboratories meeting the criteria for application.

List/Directory of Accredited Labs:

Int'1 Recognition/

Agreements:

None.

Other

Recognition:

The NRTL program is recognized by approved State occupational Safety and Health Plans. 
Department/Agency: Department of Labor (DOL)

cocumational Safety \& Health Administration (OSHA)

Blood Iead Program Director

P. O. Box 65200, Salt Lake City, UT 84165-0200

or

1781 S. 300 W, Salt Lake City, UT 84115

Phone:

(801) $524-4270$

Program Title: Blood Lead Program.

Date Established: 1979.

Description: Evaluates proficiency testing data and approves laboratories which meet OSHA accuracy requirements for blood lead analysis under the OSHA lead standards.

Fields of Testing: Biological.

Products Tested: Blood for lead.

Standards/Test Requirements for accreditation are available from the Blood

Methods:

Assessment

Criteria/

Procedures:

Lead Program Director, DOL - OSHA, P. O. Box 65200,

Salt Lake City, UT 84165-0200.

Submission of Appropriate Documentation

Independence (No Conflict-of-Interest)

Financial Stability

On-site Inspection

Staff Qualifications Requirements

Adequate Q.A. System

Sample control/Integrity Requirements

Recordkeeping Requirements

Test Report content/Format Requirements

Available operational Manuals/Instructions

Periodic Random Re-audit of Facilities

Periodic Scheduled Re-audit of Facilities

Participation in a Proficiency Testing Program $\mathrm{x}$

Adequacy of Facilities \& Equipment

Equipment Maintenance/Calibration Requirements

other

Other Information: Requirements are based solely on the results of proficiency testing.

Accreditation

Terminology:

Uses the term, "approved," meaning a laboratory that has received a satisfactory grade in blood lead proficiency testing in the prior 9 months.

Compliance: Mandatory for laboratories wishing to supply data - lead monitoring requirements of OSHA require test data be from an OSHA approved laboratory.

Authority: $\quad$ OSHA Iead Standard, 29 CFR Part 1910.1025. 
Fees:

Accreditation

Action Frequency:

Assessors:

Appeal Procechure:

Publications:

List/Directory of Accredited Iabs:

Logo:

No. of Labs:

Availability of Accreditation:
None from OSHA, some proficiency testing programs do charge fees.

Quarterly proficiency testing samples.

OSHA staff using proficiency test results from govermmental and private prograrns.

Normal U.S. federal agency due process procedures.

"OSHA List of Laboratories Approved for Blood Lead

Analysis," program information and instructions are available.

"OSHA List of Laboratories Approved for Blood Lead Analysis." None.

Approximately 165 laboratories as of 5/90.

Open to all U.S. and foreign private sector and government laboratories.

Int'1 Recognition/

Agreements: None.

Other

Recognition: None 
Department/Agency: Department of Labor (DOL)

Received: $3 / 90$

Occupational Safety \& Health Administration (OSHA)

Office of Construction \& Maritime Compliance Assistance

Rm. N-36010

200 Constitution Avenue, NW

Washington, DC 20210

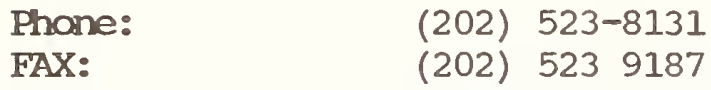

Program Title: Maritime Cargo Gear Accreditation and Certification Program.

Date Established: 1971.

Description: $\quad$ OSHA's cargo gear accreditation program is essentially one of third-party providing impartial inspection of certain maritime cargo gear handling devices specifically required to be certified under OSHA's Maritime Safety and Health

standards. The organization does not have to be a laboratory, though it must be capable of conducting the required

testing. U.S. inspected vessels which fall under the exclusive jurisdiction of the U.S. Coast Guard and foreign flag vessels are excluded.

Fields of Testing: Mechanical, electrical and non-destructive.

Products Tested: cranes, derricks, and other maritime material handling devices.

Standards/Test

Methods:

Assessment

Criteria/

Procedures:
A list of standards/test methods for which laboratories may be accredited is contained in 29 CFR Part 1919.

Submission of Appropriate Documentation

Independence (No Conflict-of-Interest)

Financial stability

On-site Inspection

Staff Qualifications Requirements

Adequate Q.A. System

Sample Control/Integrity Requirements

Recordkeeping Requirements

Test Report Content/Format Requirements

Available operational Manuals/Instructions

Periodic Random Re-audit of Facilities

Periodic Scheduled Re-audit of Facilities

Participation in a Proficiency Testing Program

Adequacy of Facilities \& Equipment

Equipment Maintenance/Calibration Requirements

other - An accredited agency must perform at

least 1500 hours of vessel gear certification

work each year in order to maintain accredited

status.

Other Information: This program is not necessarily for laboratories. It is open to third-party agencies with appropriate test equipment traceable back to NIST and capable of conducting on-site inspection of cranes, derricks, and other material handling 
Accreditation

Terminology:

Compliance:

Authority:

Fees:

Accreditation Action Frequency:

Assessors:

Proficiency

Testing Program: None.

Appeal Procedure: Normal U.S. federal agency due process appeals mechanisms.

Publications:

Logo:

No. of Entities:

Availability of Accreditation:

List/Directory of Accredited Labs:

Int'l Recognition/ Agreements:

Other

Recognition:

devices in the maritime industry. Requirements are compatible with those of the International Labor Organization Convention No. 32 .

Uses the term, "accredited," meaning an applicant for accreditation which is staffed by individuals technically qualified to conduct the inspections and examinations.

Mandatory.

29 CFR Parts 1912, 1917, 1918, and 1919.

None.

Accreditation is reissued every 1 to 3 years dependent upon demonstrated experience/expertise.

OSHA Office of Maritime Compliance Assistance staff.

Application kit with full program information, the Federal Register for notification purposes and a list of accredited agencies are available.

None.

134 laboratories as of March 5, 1990.

Open to all qualified organizations or individuals in the maritime industry. These do not have to be laboratories.

A list entitled "Certification Agencies Accredited by the Occupaticnal Safety and Health Administration Under Title 29, Chapter XVII part 1919 is available from the above address.

Accreditation is recognized by the International Labor Organization (ILO).

Accreditation is recognized by the coast Guard, and various states. 
Department/Agency: Department of Transportation (DOT)

Received: $4 / 90$

United States coast Guard

Chief, Merchant Vessel Inspection Division

(G-MVI-3)

2100 second Street, SW

Washington, DC 29593-0001

Phone: $\quad$ 202-426-1444

FAX: $\quad 202-267-1069$

Telex: $\quad 892427$

Program Title: Lifesaving, Engineering, Fire Protection, and Pollution

Prevention Equipment for Recreational Boats and Commercial

Vessels.

Date Fstablished: 1960.

Description: Accredited laboratories test equipment to standards identified by the coast Guard. Equipment is then either certified by the laboratory, or approved by the coast Guard after review of the laboratory test report.

Fields of Testing: Biological, chemical, electrical, mechanical, optics and photometry, thermal.

Products Tested: Marine safety survival, fire protection and pollution prevention equipment.

Standards/Test

Methods:

List is available from the above address.

Assessment

Criteria/

Procedures:

Submission of Appropriate Documentation

Independence (No conflict-of-Interest)

Financial stability

on-site Inspection

Staff Qualifications Requirements

Adequate Q.A. System

Sample Control/Integrity Requirements

Recordkeeping Requirements

Test Report Content/Format Requirements

Available Operational Manuals/Instructions

Periodic Random Re-audit of Facilities

Periodic Scheduled Re-audit of Facilities

Participation in a Proficiency Testing Program

Adequacy of Facilities \& Equipment

Equipment Maintenance/Calibration Requirements $\underline{x}$

other

Other Information: The accreditation requirements generally follow the guidelines suggested in the American Society of Testing and Materials (ASTM) E548, "Practice for Preparation of Criteria for Use in the Evaluation of Testing and Inspection Bodies;" however, ASTM E548 is very general and not sufficient as a standard for evaluation. 
Accreditation

Terminology:

Campliance:

Authority:

Fees:

Aocreditation

Action Frequency: Accreditation is valid until withdrawn.

Assessors:

U.S. Coast Guard engineers.

Proficiency

Testing Program: None is currently employed.

Appeal Procedure: Normal U.S. federal agency due process appeals mechanisms.

Publications: $\quad 46$ CFR Part 159.010.

Logo:

No. of Labs:

Availability of Accreditation:

Uses the term, "listed," meaning an independent laboratory that has been found acceptable under an applicable subpart of the provisions of 46 CFR 159.010-11.

Mandatory to obtain certification or approval.

46 CFR Part 159.010.

None.

None.

59 laboratories as of March 30, 1990.

open to all U.S. and state govermment laboratories, private sector laboratories, foreign government and private sector laboratories.

List/Directory of None published, but a List of Coast Guand Accepted Independent Accredited Labs: Laboratories and Inspection Agencies list is available upon request.

Int'l Recognition/

Agreements: None.

Other

Recognition: None. 
Department/Agency: Department of Transportation (DOT)

Received: $4 / 90$

United States coast Guard

Marine Technical \& Hazardous Materials Division

Chief, Engineering Branch

(G-MIH-2)

2100 Second Street, SW

Washington, DC 29593-0001

Phone: $\quad$ 202-267-2206

FAX: 202-267-0025

Program Title: Approval of equipment for use in hazardous areas aboard commercial vessels.

Date Fstablished: 1960.

Description: The U.S. Coast Guard requires electrical equipment in hazardous areas on U.S. Coast Guard certified vessels to be "listed" by an independent testing laboratory recognized by the commandant.

Fields of Testing: Electrical, mechanical, non-destructive.

Products Tested: Electrical enclosures, wiring and cabling.

Standards/Test Laboratories are accredited to Articles 500-503 of the

Methods:

National Electrical Code (NEC) and NFPA No. 496.

Assessment

Criteria/

Procedures:

Submission of Appropriate Documentation

Independence (No Conflict-of-Interest)

Financial Stability

on-site Inspection

Staff qualifications Requirements

Adequate Q.A. System

Sample control/Integrity Requirements

Recordkeeping Requirements

$\begin{array}{ll}\text { Test Report Content/Format Requirements } & \mathrm{x} \\ \text { Available Operational Manuals/Instructions } & \underline{\mathrm{x}}\end{array}$

Periodic Random Re-audit of Facilities

Periodic Scheduled Re-audit of Facilities

Participation in a Proficiency Testing Program

Adequacy of Facilities \& Equipment

Equipment Maintenance/Calibration Requirements $\frac{\mathrm{x}}{\mathrm{x}}$

Other

Other Information: The accreditation requirements generally follow the guidelines suggested in the American Society of Testing and Materials (ASTM) E548, "Practice for Preparation of Criteria for Use in the Evaluation of Testing and Inspection Bodies;" however, ASTM E548 is very general and not sufficient as a standard for evaluation.

Accreditation

Terminology:

Uses the term, "listed," meaning an independent laboratory that has been found acceptable under an applicable subpart of the provisions of 46 CFR 159.010-11. 


\begin{tabular}{|c|c|}
\hline Compliance: & Mandatory. \\
\hline Authority: & 46 CFR Part 159.010 \\
\hline Fees: & None. \\
\hline Accreditation & \\
\hline Action Frequency: & Accreditation is valid until withdrawn. \\
\hline Assessors: & U.S. Coast Guard engineers. \\
\hline Proficiency & \\
\hline Testing Program: & None is currently employed. \\
\hline Appeal Procecture: & Normal U.S. federal agency due process appeals mechanisms. \\
\hline Publications: & 46 CFR Part 159.010 \\
\hline Logo: & None, though USCG requires product marking by test lab. \\
\hline No. of Labs: & Four laboratories as of March 30, 1990. \\
\hline $\begin{array}{l}\text { Availability of } \\
\text { Accreditation: }\end{array}$ & $\begin{array}{l}\text { Open to all U.S. laboratories, foreign govermment and foreign } \\
\text { private sector laboratories. }\end{array}$ \\
\hline $\begin{array}{l}\text { List/Directory of } \\
\text { Accredited Labs: }\end{array}$ & None published, but a list is available upon request. \\
\hline $\begin{array}{l}\text { Int'1 Recognition/ } \\
\text { Agreements: }\end{array}$ & None. \\
\hline $\begin{array}{l}\text { Other } \\
\text { Recognition: }\end{array}$ & None. \\
\hline
\end{tabular}


Department/Agency: Department of Transportation (DOT)

Received: $9 / 90$

United States coast Guard

Merchant Vessel Inspection and Documentation Division

2100 second Street, SW

Washington, DC 29593-0001

$\begin{array}{ll}\text { Phone: } & 202-267-2978 \\ \text { FAX: } & 202-267-1069 \\ \text { Telex: } & 892427 \text { coast Guard - WSH }\end{array}$

Program Title: Delegated approval authorities for safety approval of cargo containers.

Date Established: May 22, 1978.

Description:

To delegate to qualified persons or organizations the authority to approve, on behalf of the coast Guard, cargo containers used in international transport in accordance with the Intermational convention for Safe containers (CSC).

Fields of Testing: Mechanical.

Products Tested: Cargo containers.

Standards/Test International convention for safe containers (CSC) formed at Methods:
Assessment

Criteria/

Procedures:
Geneva, December, 1972, and ratified by the United States on January 3, 1978, as implemented by 49 CFR Part 450-453.

Submission of Appropriate Documentation

Independence (No conflict-of-Interest)

Financial Stability

on-site Inspection

Staff oualifications Requirements

Adequate Q.A. System

Sample control/Integrity Requirements

Recordkeeping Requirements

Test Report content/Format Requirements

Available operational Manuals/Instructions

Periodic Random Re-audit of Facilities

Periodic Scheduled Re-audit of Facilities

Participation in a Proficiency Testing Program

Adequacy of Facilities \& Equipment

Equipment Maintenance/Calibration Requirements

other

Other Information: The accreditation requirements generally follow the guidelines suggested in the American Society of Testing and Materials (ASTM) E548, "Practice for Preparation of Criteria for Use in the Evaluation of Testing and Inspection Bodies." More emphasis is placed on the individual or agency as to organization resources such as independence from manufacturer influence and financial independence. A detailed application is required. An on-site inspection may be conducted. Initial and follow-up and on-site visits are random in nature and dependent on report review information. Records of approvals issued and backup information must be kept for 15 years and 
Aocreditation Terminology:

Compliance:

Authority:

Fees:

Aocreditation

Action Frequency:

Assessors:

Proficiency

Testing Program: None is currently employed.

Appeal Procedure: In addition to normal federal due process, detailed appeals are spelled out in the 49 CFR Part 450-453 regulations.

Publications:

Logo:

No. of Labs:

Availability of Accreditation:

become property of the coast Guard if approval is withdrawn or otherwise terminated. Requirements are also comparable to those contained in the International convention for Safe Containers (CSC) dated 12/72 and ratified by the U.S. $1 / 3 / 78$.

Uses the term, "delegated," meaning delegate of the commandant of the coast Guard authorized to approve containers.

Voluntary for delegation agencies; mandatory as to the product (cargo containers).

For purposes of the international convention for safe containers regulations contained in 49 CFR Part 450-453.

The program is without fee to the accredited delegated approval authority. Each authority "shall establish and make available to the public a schedule of fees for the approval of services performed under these regulations, the fees must not be disproportional to the costs (including transportation expense, if any) actually incurred."

Accreditation is valid until withdrawn.

Representatives of U.S. Coast Guard.

Regulations are contained in the Federal Register, 20 April 1978, revised 2 June 1980; and list of delegated approval authorities.

Identification code assigned by Chief, Merchant Vessel Inspection Division, U.S. Coast Guard, to the approval authority.

13 laboratories as December 1, 1989.

open to all U.S. laboratories; and foreign private sector laboratories if their own government is not a signatory to the (CSC) .

List/Directory of A list entitled, "United States Authorities for the Accredited Labs: International convention for Safe containers," is available.

Int'l Recognition/ Inherent in the scope of program based upon a ratified U.S. Agreements: foreign convention.

Other

Recognition: None. 
Department/Agency: Department of Treasury

Received: $3 / 90$

United States customs Service

Office of Laboratories \& Scientific Services

Room 7113

1301 Constitution Ave., NW

Washington, DC 20229

Phone: $\quad 202-566-5853$

FAX: $\quad 202-343-0345$

Program Title: Petroleum gaugers and commercial laboratory program.

Date Established: 1973

Description: Accredits commercial laboratories to test petroleum, petroleum products, and organic chemicals in bulk and liquid form for customs purposes.

Fields of Testing: Chemical.

Products Tested: Petroleum, petroleum products, bulk/liquid organic chemicals.

Standards/Test List of requirements for accreditation is available from the Methods: above address. The Office of Laboratories and Scientific Services uses standards based on methods found in the American Society for Testing and Materials (ASTM) publications, and the American Petroleum Institute (API) standards.

Assessment Criteria/ Procedures:
Submission of Appropriate Documentation Independence (No Conflict-of-Interest)

Financial Stability

on-site Inspection

Staff Qualifications Requirements

Adequate Q.A. System

Sample Control/Integrity Requirements

Recordkeeping Requirements

Test Report Content/Format Requirements

Available Operational Manuals/Instructions

Periodic Random Re-audit of Facilities

Periodic Scheduled Re-audit of Facilities

Participation in a Proficiency Testing Program

Adequacy of Facilities \& Equipment

Equipment Maintenance/Calibration Requirements $\frac{\mathrm{x}}{\mathrm{x}}$

other - A bond is required as well as the successful completion of a background investigation

Other Information: Requirements are comparable to those contained in ASTM E548, "Practice for Preparation of Criteria for Use in the Evaluation of Testing and Inspection Bodies," and those contained in relevant ISO documents.

Accreditation Terminology:
Uses the term, "accredited," meaning that a positive determination has been made that the applicant is competent, independent, and reputable. 
Compliance:

Authority:

Fees:

Accreditation

Action Frequency:

Assessors:

Proficiency

Testing Program:

Appeal Procedure:

Publications:

Logo:

No. of Labs:

Availability of Accreditation:

List/Directory of Accredited Labs:
Mandatory if results of measurements and analyses are used for customs purposes.

19 CFR Part 151.13.

None.

Because gauger services are ongoing, monitoring by appropriate local customs staff is essentially continuing. Accreditation is not reissued.

Office of Laboratories and Scientific Services personnel.

A random sampling program is conducted. Samples are submitted to customs field laboratories for confirmatory analysis.

Normal U.S. federal agency due process appeals mechanisms. An accredited laboratory may also appeal a decision to the commissioner of customs.

19 CFR Part 151.13. A list of requirements for accreditation is also available from the above address.

None.

30 laboratories as of $3 / 1 / 90$.

Available to all U.S. laboratories.

Lists of accredited laboratories are published in the Federal Register and the customs Bulletin.

Int'l Recognition/ None. Commercial laboratories are accredited by the U.S. Agreements: Customs Service to provide analytical data unique to U.S. customs requirements.

Other Recognition:
None. Commercial laboratories are accredited by the U.S. Customs Service to provide analytical data unique to U.S. customs requirements. 
Department/Agency: Department of the Treasury

Bureau of Alcohol, Tobacco and Firearms (ATF)

Office of Laboratory Services, Room 253

1401 Research Boulevard

Rockville, MD 20850

Phone: $\quad$ (301) 294-0410

FAX:

(301) $443-4419$

Program Title: Certification of U.S. laboratories for the analysis of wines and distilled spirits for export.

Date Established: Distilled spirits beverages: 1969. Wines: 1973.

Description: ATF certifies laboratories qualified for the analysis of wines and distilled spirits beverages to meet the requirements of certain countries which require that U.S. wines and/or distilled spirits beverages exported to those countries be accompanied by a chemical analysis performed by a laboratory certified by ATF.

Fields of Testing: Chemical.

Products Tested: Distilled spirits beverages, wines.

Standards/Test

Methods:

Internal Revenue Procedure 69-22 (Distilled Spirits). ATF Procedure 86-3 (Wines).

Assessment

criteria/

Submission of Appropriate Documentation

Independence (No Conflict-of-Interest)

Procedures:

Financial Stability

On-site Inspection

Staff qualifications Requirements

Adequate Q.A. System

Sample control/Integrity Requirements

Recordkeeping Requirements

Test Report Content/Format Requirements

Available Operational Manuals/Instructions

Periodic Random Re-audit of Facilities

Periodic Scheduled Re-audit of Facilities

Participation in a Proficiency Testing Program

Adequacy of Facilities \& Equipment

Equipment Maintenance/Calibration Requirements

other -

Other Information: Laboratories are required to send copies of school

transcripts and other pertinent information on their personnel.

Accreditation

Terminology:

Uses the term "certified."

Compliance:

Mandatory only for laboratories wishing to be certified by the Bureau of Alcohol, Tobacco and Firearms. 
Authority:

Fees:

Accreditation

Action Frequency

Assessors:

Proficiency

Testing Program: None.

Appeal Procedure: Normal U.S. federal agency due process appeals mechanisms.

Publications:

Logo:

No. of Labs:

Availability of

Accreditation:

List/Directory of Accredited Labs:

Int'l Recognition/

Agreements:

As established by individual countries

Other Recognition: None. 
Department/Agency: Department of Veterans Affairs (VA)

Received: $3 / 90$

Veterans Health Services \& Research Administration (VHS\&RA)

Pathology Service (113)

810 Vermont Ave., NW

Room 933

Washington, DC 20420

Phone: $\quad$ (202) 233-7469

FAX:

(202) $233-4756$

Program Title: College of American Pathologists (CAP) Inspection and Accreditation Program and related quality control programs.

Date Established: 1970.

Description: A centralized contract through the VA Marketing Center is established annually to provide quality control, inspection, and accreditation of clinical laboratories, special function laboratories and nuclear medicine laboratories numbering 408 in the VA system. This contract is monitored by the Pathology Service, VA. A quality control program has also been established through the American Society of Clinical Pathologists (known as CheckPath) to help assess physicians' diagnostic skills. All full time physicians in the VA system will be enrolled. The VA also monitors its histopathology program through the Armed Forces Institute of Pathologists.

Fields of Testing: Clinical, chemical, nuclear, biological.

Products Tested: Clinical samples.

Standards/Test Methods:

Assessment Criteria/ Procedures:

College of American Pathologists Laboratory Accreditation Program (CAPLAP) standards and test methods.

Submission of Appropriate Documentation

Independence (No Conflict-of-Interest)

$\frac{\mathrm{x}}{\mathrm{n} / \mathrm{a}}$

Financial Stability

On-site Inspection

Staff Qualifications Requirements

Adequate Q.A. System

Sample Control/Integrity Requirements

Recordkeeping Requirements

Test Report content/Format Requirements

Available operational Manuals/Instructions

Periodic Random Re-audit of Facilities

Periodic Scheduled Re-audit of Facilities

Participation in a Proficiency Testing Program $\frac{x}{x}$

Adequacy of Facilities \& Equipment

Equipment Maintenance/Calibration Requirements $\mathrm{x}$

other

Accreditation

Terminology:

Uses the term "accredited," as defined by the CAP.

Compliance:

Mandatory for all VA facilities covered by the program. 
Authority: $\quad$ N/A.

Fees:

Accreditation

Action Frequency:

Assessors:

\section{Proficiency}

Testing Program:

Appeal Procedure: Deficiencies are cited. A time frame is provided for

correction. If deficiencies are corrected, then accreditation is granted.

Publications: None, though documentation is maintained by Pathology Service, local VA laboratories, and at CAP.

Logo:

№. of Labs:

Fees are negotiated between CAP and the VA.

Accreditation is reissued every 2 years with a selfinspection required in the interim year.

A group of physicians and technologists assembled by CAP. They are from both the government and private sector.

Participation in proficiency testing is required.

Authorized certificate issued by CAP.

There are 408 VA laboratories covered by this program as of $3 / 1 / 90$.

Availability of Accreditation:

This program is open to VA laboratories only, though CAP provides accreditation for all laboratories.

List/Directory of A list is available from the College of American Pathologists, Aocredited Labs: 325 Waukegan Rd., Northfield, IL, Phone: (708) 446-8800.

Int'l Recognition/

Agreements:

No special agreements other than ones that CAP may have.

Other Recognition: The CAP program is recognized by many organizations. 



\section{APPENDIX I - INDICES}

INDEXX

PAGE

GOVETIMENT NATIONAL AOCREDITATION SYSTEMS. . . . . . . 72

AGENCY INDEX BY ACRONYM......................... 74

DEPARTMENT/AGENCY INDEX. ........................ 75

AGENCY INDEX.............................. 77

INDEX BY FTETD OF TIESTING................... 78

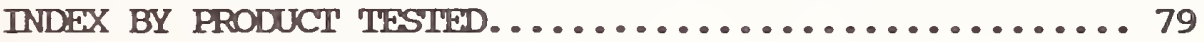


Department of Agriculture (USDA), Animal \& Plant Health Inspection Service (APHIS), Veterinary Service (VS), Science and Technology, Accreditation of laboratory facilities for contagious equine metritis (CEM) .

Department of Agriculture (USDA), Federal Grain Inspection Service (FGIS), Compliance Division, Grain and commodity inspection and weighing (including equipment, scale and weight testing).

Department of Agriculture (USDA), Food Safety \& Inspection Service (FSIS), Science \& Technology, Chemistry Division, Accredited laboratory program.

Department of Agriculture (USDA), Office of Transportation (OT), ATP Manager, Agreement on the International Carriage of Perishable Foodstuffs and on the Special Equipment to be Used for Such Carriage (ATP) .

Department of Commerce (DOC), National Institute of Standards \& Technology (NIST), Office of Weights \& Measures (OWM), State laboratory program.

Department of commerce (DOC), National Institute of Standards \& Technology (NIST), National Voluntary Laboratory Accreditation Program (NVLAP) •

Department of Defense (DOD), Army Corps of Engineers (CE), CE district, project and commercial laboratories assurance inspection program.

Department of Defense (DOD), Defense Electronics Supply Center (DESC), Qualification Division (EQ), Qualified Product/Manufacturer Lists (QPL/QML) .

Department of Defense (DOD), Defense Logistics Agency (DLA), Defense Personnel Support center (DNSC), Qualified Laboratory List (QLI))

Envirommental Protection Agency (EPA), Office of Drinking Water, Monitoring \& Exposure Section, Drinking water laboratory certification program.

Environmental Protection Agency (EPA), Office of Mobile Sources, Emission Control Technology Division, Retrofit Device Evaluation Program.

Envirommental Protection Agency (EPA), Office of Air Quality Planning and Standards, Technical Support Division, Wood Stoves New Source Performance Standards Laboratory Accreditation.

Federal Communications Commission (FCC), Office of Engineering \& Technology, Authorization \& Evaluation Division, Equipment Authorization Branch, Description of Measurement Facilities.

Department of Health \& Human Services (HHS), Alcohol, Drug Abuse, \& Mental Health Administration (ADAMHA), National Institute on Drug Abuse, Division of Applied Research, Drug Testing Section, National Laboratory Certification Program (NLCP).

Department of Health \& Human Services (HHS), Food Drug Administration (FDA), Bioresearch Program, Toxicology laboratory monitoring program.

Department of Health \& Human Services (HHS), Food \& Drug Administration (FDA), Center for Food Safety and Applied Nutrition, Lab. QA Branch, Evaluation of milk laboratories. 
Department of Health \& Human Services (HHS), Health Care Financing Administration (HCFA), Clinical Laboratories Improvement Act.

Department of Housing \& Urban Development (HUD), Office of Architecture \& Engineering, Materials Acceptance Division, Technical suitability of building products program.

Department of Interior (DOI), Office of Surface Mining Reclamation \& Enforcement (OSM), Division of Technical Services, Small operator Assistance Program (SOAP).

Department of Labor (DOL), Mine Safety \& Health Administration (MSHA),

Approval \& Certification Center (A\&CC), Accreditation of laboratories for MSHA approval or certification.

Department of Labor (DOL), Mine Safety \& Health Administration (MSHA), Approval \& Certification Center (A\&CC), Testing and Evaluation of Illumination Systems.

Department of Labor (DOL), Mine Safety \& Health Administration (MSHA), Approval \& Certification Center (A\&CC), Testing by Applicant or Third Party.

Department of Labor (DOL), Occupational Safety Health Administration (OSHA) Office of Variance Determination, Nationally Recognized Testing Laboratories (NRTL) Program.

Department of Labor (DOL), Occupational Safety \& Health Administration (OSHA), Blood Lead Program.

Department of Labor (DOL), Occupational Safety \& Health Administration (OSHA), Office of Construction \& Maritime Compliance Assistance, Maritime Cargo Gear Accreditation and certification Program.

Department of Transportation (DOT), United States coast Guard, Merchant Vessel Inspection Division, Lifesaving, Engineering, Fire Protection, and Pollution Prevention Equipment for Recreational Boats and commercial Vessels.

Department of Transportation (DOT), United States Coast Guard, Marine Technical \& Hazardous Materials Division, Engineering Branch, Approval of equipment for use in hazardous areas aboard commercial vessels.

Department of Transportation (DOT), United States Coast Guard, Merchant Vessel Inspection and Documentation Division, Delegated approval authorities for safety approval of cargo containers.

Department of Treasury, United States Customs Service, Office of Laboratories \& Scientific Services, Petroleum gaugers and commercial laboratory program.

Department of Treasury, Bureau of Alcohol, Tobacco and Firearms, Office of Laboratory Services, Certification of U.S. Laboratories for the Analysis of Wines and Distilled Spirits for Export.

Department of Veterans Affairs (VA), Veterans Health Services \& Research Administration (VHS\&RA), Pathology Service, College of American Pathologists (CAP) Inspection and Accreditation Program and related quality control programs. 
This index may be used by readers to learn what certification programs a particular agency operates when only the agency's acronym or other limited designation is known. Agencies are listed alphabetically by acronym/designation.

\section{ACRONYM}

\section{PAGE}

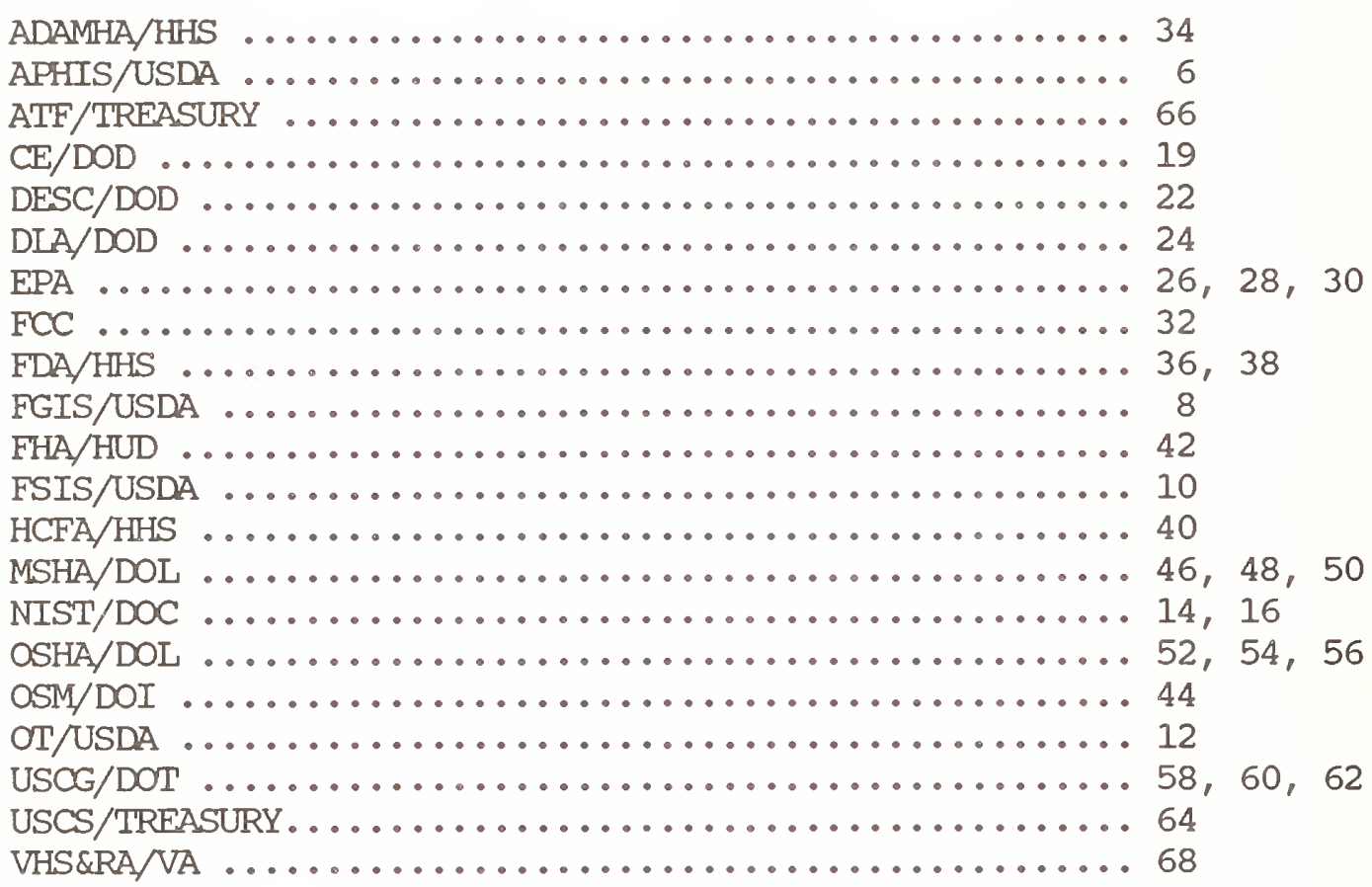


This index may be used by readers to learn what certification programs a particular department and/or departmental agency operates when both the department and agency's names are known. Departments are listed alphabetically, followed by a listing of independent federal agencies.

\section{DEPARTMENIS/INDEPENDENT AGENCY}

PAGE

DEPARIMENT OF AGRICULTURE

Animal \& Plant Health Inspection Service (APHS) ............ 6

Federal Grain Inspection Service (FGIS) $\ldots \ldots \ldots \ldots \ldots \ldots \ldots \ldots \ldots . \ldots$

Food Safety \& Inspection Service (FSIS) $\ldots \ldots \ldots \ldots \ldots \ldots \ldots \ldots \ldots$

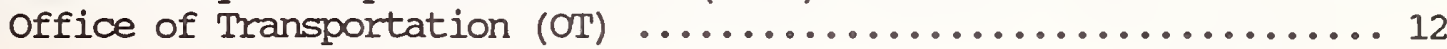

DEPARTMENT OF COMMERCE

National Institute of Standards \& Technology (NIST)

Office of Weights \& Measures (OWM) ................... 14

National Voluntary Laboratory Accreditation Program (NVIAP) 16

DEPARTMENT OF DEFENSE

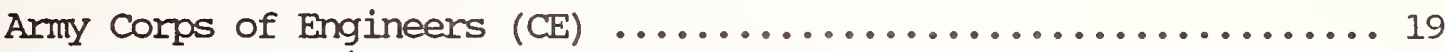

Defense Electronics Supply Center (DESC) $\ldots \ldots \ldots \ldots \ldots \ldots \ldots \ldots \ldots \ldots . \ldots \ldots$

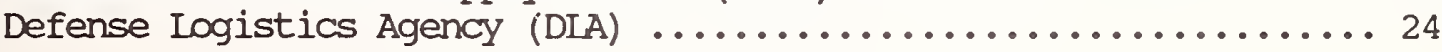

ENVIRONMENIAL PROTECITION AGENCY

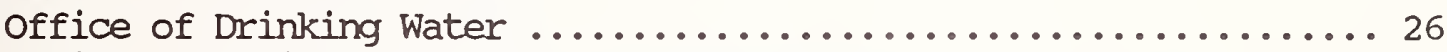

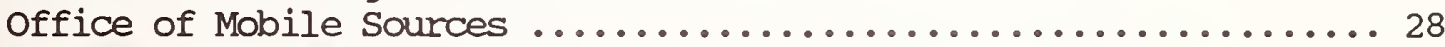

Office of Air Quality Planning and Standards ................ 30

FEDERAL COMMUNICATIONS COMMISSION

Office of Engineering \& Technology ...................... 32

DEPARTMENT OF HEALTH \& HUMAN SERVICFS

Alcohol, Drug Abuse, \& Mental Health Administration (ADAMHA) .... 34 Food Drug Administration (FDA)

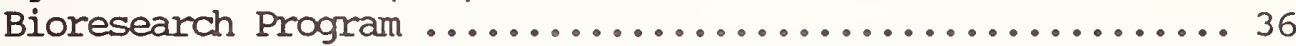

Center for Food Safety and Applied Nutrition ........... 38

Health Care Financing Administration (HCFA) ............... 40

DEPARIMFNT OF HOUSTIG \& URBAN DEVETOPMENT

Federal Housing Administration (FHA)

Office of Architecture \& Engineering ................ 42

DEPARTMENT OF INIERTIOR

Office of Surface Mining Reclamation \& Enforcement (OSM) ........44 
DEPARIMENT OF LABOR

Mine Safety \& Health Administration (MSHA)

Approval \& Certification Center $(A \& C C) \ldots \ldots \ldots \ldots \ldots \ldots . . \ldots 6,48,50$

occupational Safety Health Administration (OSHA)

Office of Variance Determination .................. 52

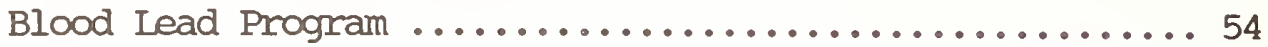

Office of Construction \& Maritime Cormpliance Assistance . 56

DEPARTMENT OF TIRANSPORTATION

United States coast Guard

Merchant Vessel Inspection Division ............... 58

Marine Technical \& Hazardous Materials Division ........ 60

Merchant Vessel Inspection and Documentation Division ... 62

DEPARTMENT OF TREASURY

United States Customs Service ....................... 64

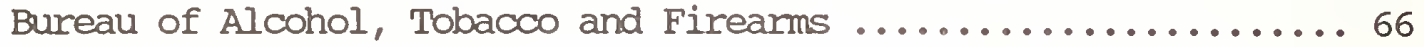

DEPARTMENT OF VEIERANS AFFAIRS

Veterans Health Services \& Research Administration (VHS\&RA) ....68 


\section{AGENCY TIDEX}

This index may be used by readers to learn what certification programs a particular agency operates when only the agency's name is known. Agency names are listed alphabetically.

\section{DEPARIMENTAL/INDEPENDENT AGENCY}

$\underline{\text { PAGE }}$

Alcohol, Drug Abuse, \& Mental Health Administration (HHS) ........ 34 Animal \& Plant Health Inspection Service (USDA) .............. 6

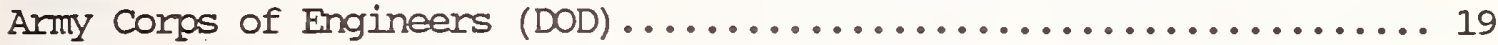
Bureau of Alcohol, Tobacco and Firearms (TREASURY) ............66 Defense Electronics Supply Center (DOD) ..................... 22 Defense Logistics Agency (DOD) .......................... 24 Federal Grain Inspection Service (USDA) $\ldots \ldots \ldots \ldots \ldots \ldots \ldots \ldots \ldots$

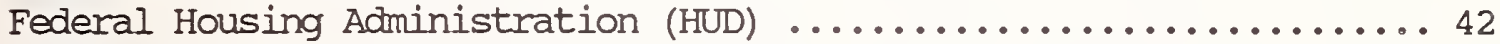

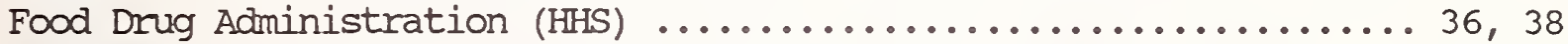
Food Safety \& Inspection Service (USDA) ..................... 10 Health Care Financing Administration (HSS) ............... 40 Mine Safety \& Health Administration (DOL) ................... 46, 48, 50 National Institute of Standards \& Technology (DOC) .............. 14, 16 Occupational Safety Health Administration (DOL) .............. 52, 54,56

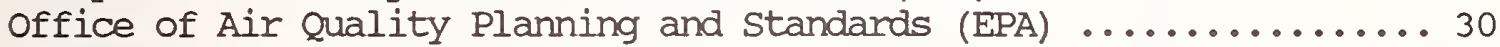

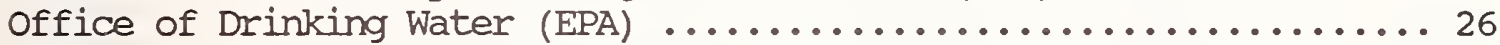

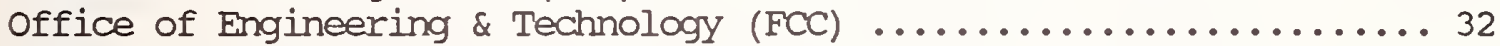

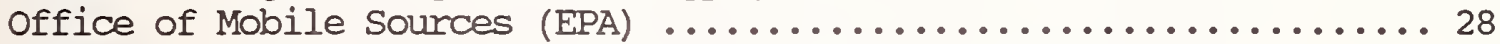
Office of Surface Mining Reclamation \& Enforcement (DOI) .........44

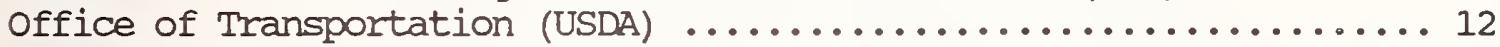
United States Coast Guard (DOT) ......................... 58, 60, 62 United States customs Service (TREAS) ......................64 64 Veterans Health Services \& Research Administration (VA) .........68 


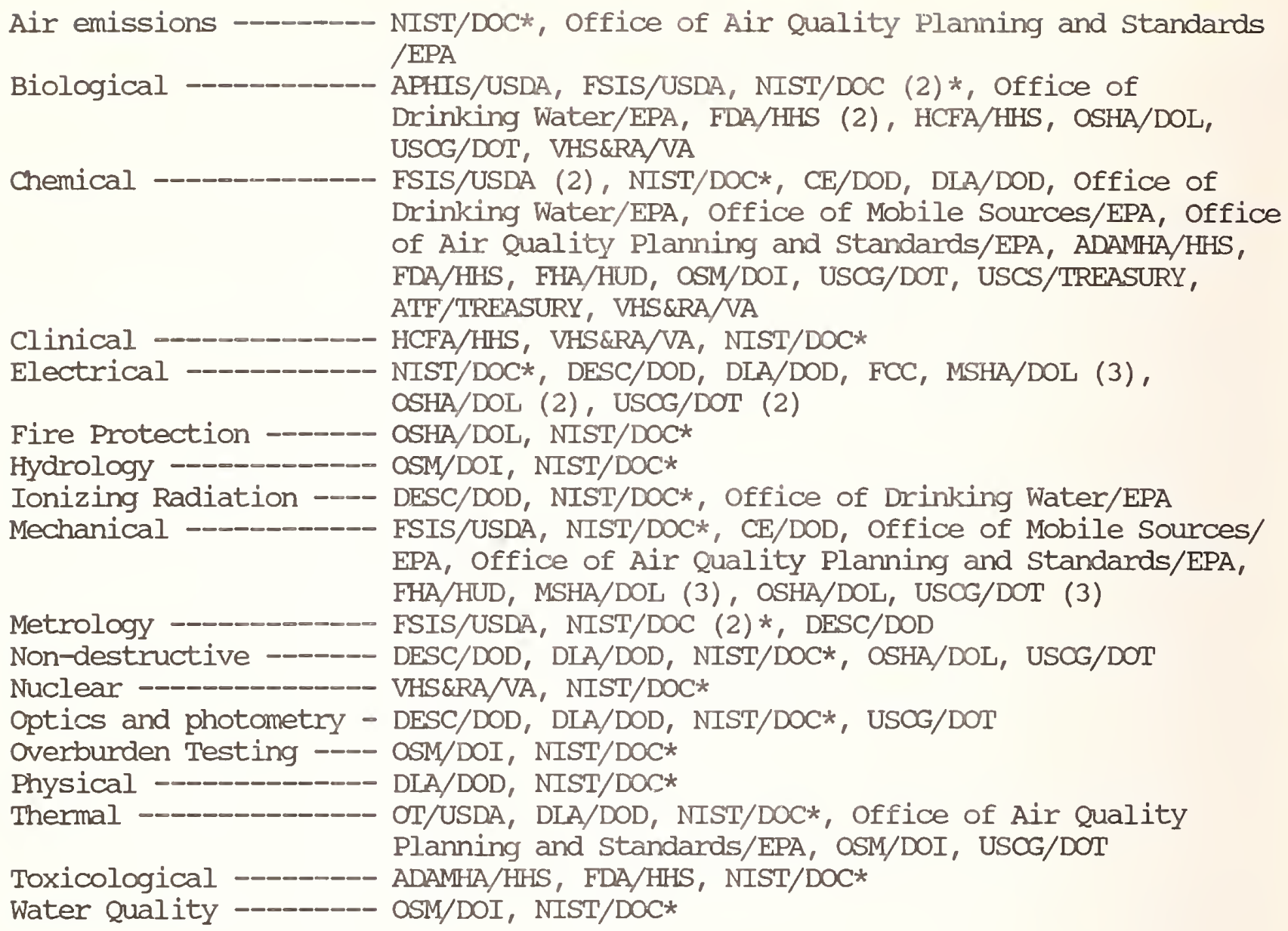

*The National Institute of Standards and Technology (NIST), National Voluntary Laboratory Accreditation Program (NVLAP) is authorized to be involved in all fields of testing for which a need is demonstrated. 


\section{BIOLOGICAL/CITINICAL/MFDICAL PRODUCIS}

biological products, human $\ldots \ldots \ldots \ldots \ldots \ldots \ldots \ldots \ldots . \ldots .34,36,40,54,68$ blood for lead ..................................

clinical samples ............................. 34, 36, 40, 54, 68

drugs, human and animal $\ldots \ldots \ldots \ldots \ldots \ldots \ldots \ldots \ldots . \ldots \ldots$

equine-related products ......................6 6

human biological products ......................34, 36, 40, 54, 68

human specimens $\ldots \ldots \ldots \ldots \ldots \ldots \ldots \ldots \ldots \ldots \ldots \ldots \ldots . \ldots . \ldots, 40,54,68$

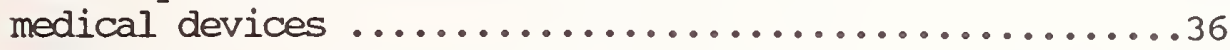

specimens ................................34, 40, 54, 68

urine specimens $\ldots \ldots \ldots \ldots \ldots \ldots \ldots \ldots \ldots \ldots \ldots \ldots . . . \ldots, 40,68$

\section{BUIIDING/CONSTRUCIION PRODUCTS}

acoustical testing services .....................16

admixtures .................................. 19

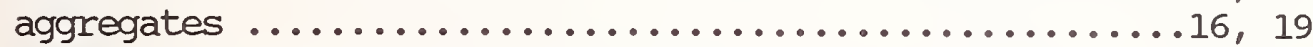

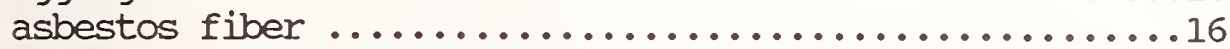

building products \& constructions .................16, 19, 42

carpet ................................. 42

cement, aggregates, \& cement based products (3) .......16, 19

commercial products ...........................16

concrete (2) ................................. 19

construction products $\ldots \ldots \ldots \ldots \ldots \ldots \ldots \ldots \ldots \ldots \ldots . \ldots \ldots, 19,42$

doors .....................................42

flooring, glued plywood .....................42

foundations ..................................19

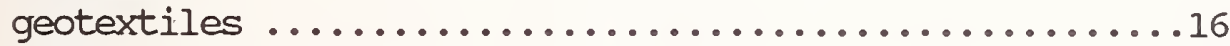

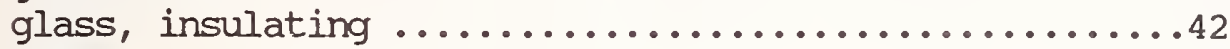

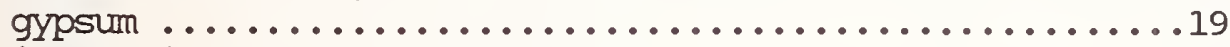

insulation materials, thermal ....................16

lumber ...................................42

lumber, pressure treated ......................42

paint ..........................................

particleboard ..............................42

plastic .....................................16

plumbing fixtures $\ldots \ldots \ldots \ldots \ldots \ldots \ldots \ldots \ldots \ldots \ldots \ldots, 42$

plywood .....................................42

road/paving materials .........................16, 19

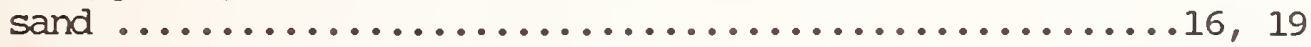

seals and sealants ............................16

siding, textured plywood .......................42

stair treads ....................................42

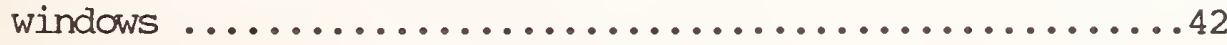

\section{EIECIRICAL/EIECTRONIC PRODUCTS}

battery assemblies ...........................50

computer applications .........................16

dosimetry, personnel radiation ..................16

electrical and related products used in the workplace ..52 
electrical cables (in hazardous areas) ...........60

electrical enclosures (in hazardous areas) .........60

electrical equipment and supplies (mining) .........46

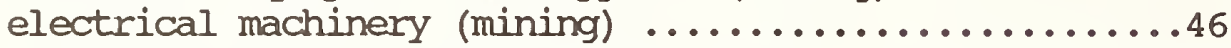

electrical wiring (in hazardous areas) ...........60

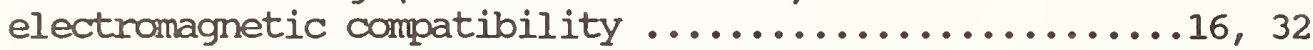

electronic products that emit radiation $\ldots \ldots \ldots \ldots \ldots \ldots, 32,36$

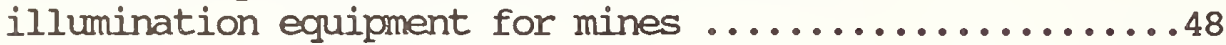

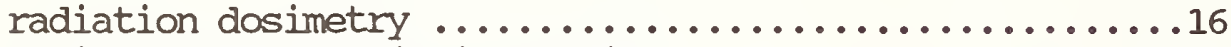

radio frequency emitting devices $\ldots \ldots \ldots \ldots \ldots \ldots \ldots \ldots, 32$

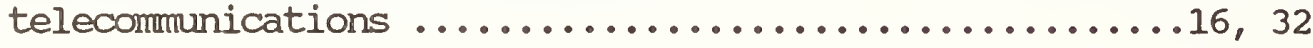

\section{ENVIRONMENIAL PRODUCTS}

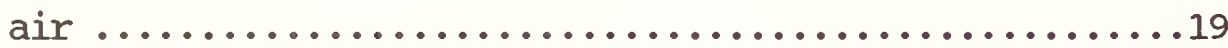

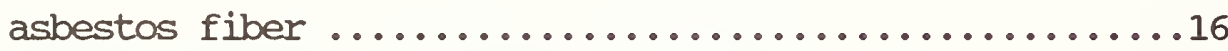

marine pollution prevention equipment ..............58

petroleum and petroleum products ...............64

pollution prevention equipment, marine $\ldots \ldots \ldots \ldots \ldots . . .58$

rock ......................................16, 19, 44

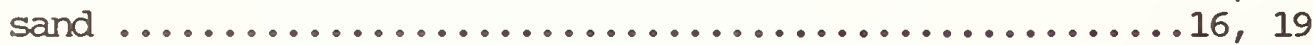

soil ........................................ 19, 44

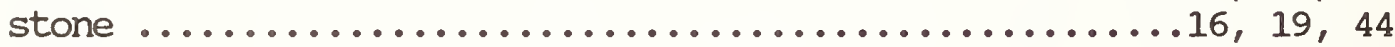

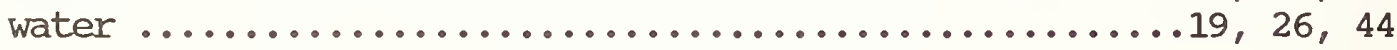

\section{FOOD AND AGRICULTURAL PRODUCIS}

alcoholic beverages .......................66

commodities for weight .................... 8

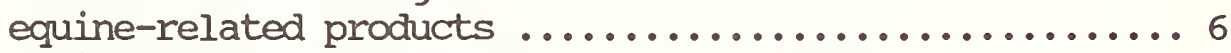

equipment for the transport of perishable foodstuffs ...12

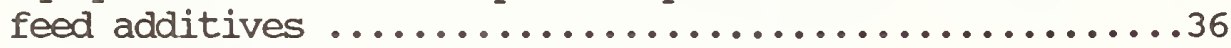

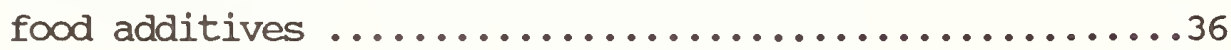

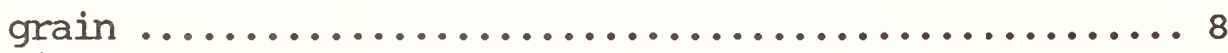

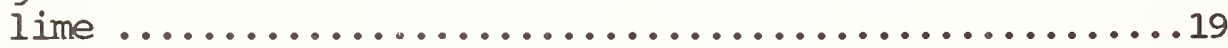

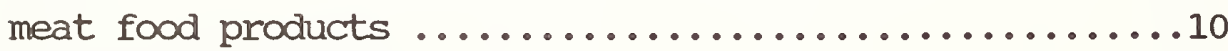

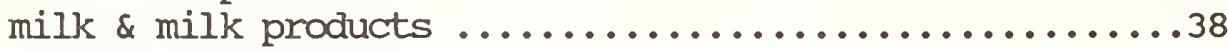

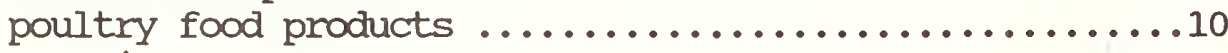

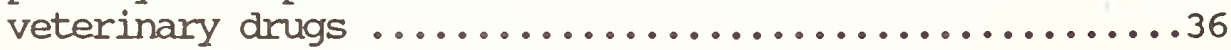

\section{MINING PRODUCTS}

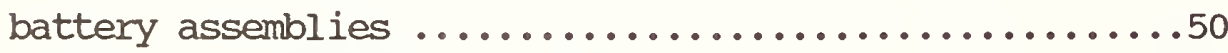

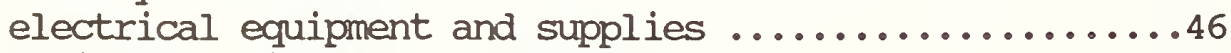

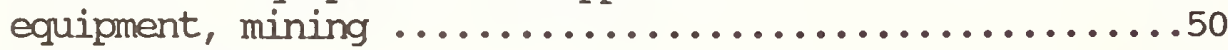

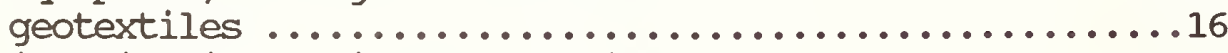

illumination equipment for mines ...............48

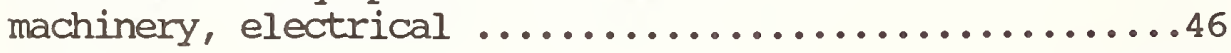

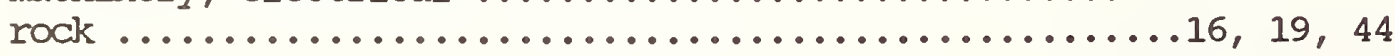

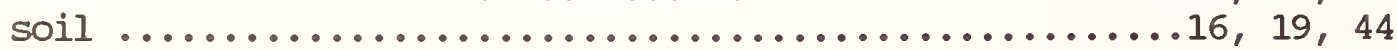




\section{MISC. CONSUMER PRODUCTS}

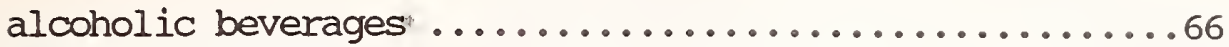

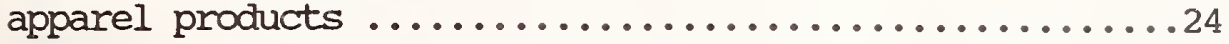

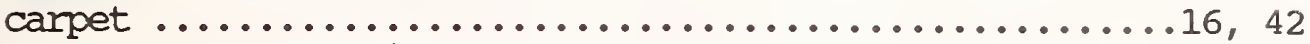

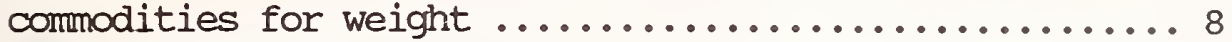

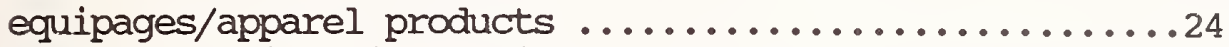

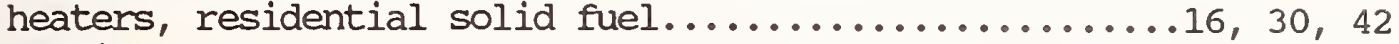

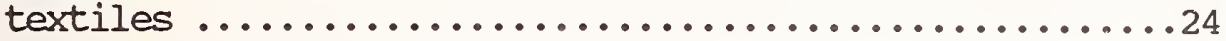

\section{TRANSPORITATION RETATED PRODUCTS}

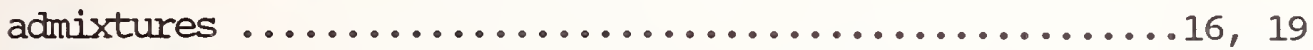

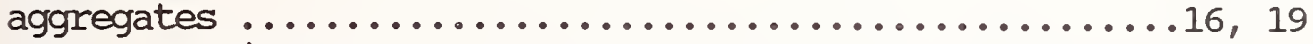

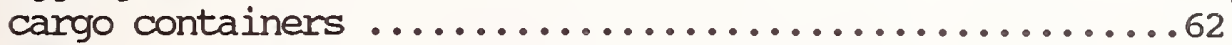

cement, aggregates, \& cement based products .............. 19

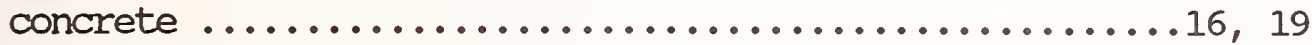

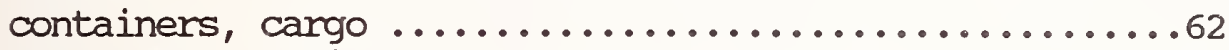

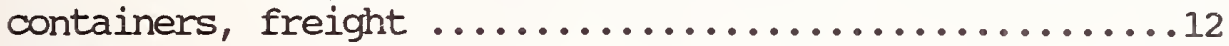

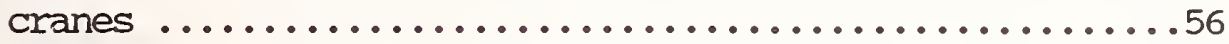

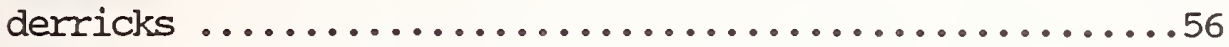

electrical and related products used in the workplace ..52

equipment for the transport of perishable foodstuffs ...12

fire protection equipment, marine ...............58

marine pollution prevention equipment ............58

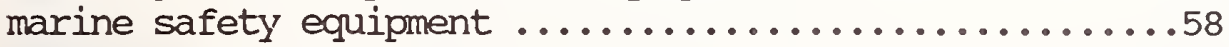

maritime material handling devices ...............56

material handling devices, maritime ..............56

pollution prevention equipment, marine ............58

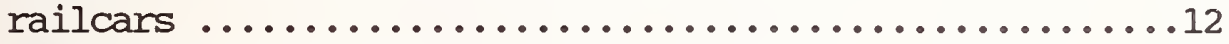

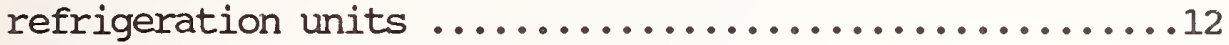

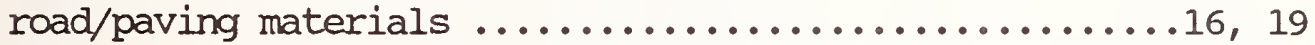

rock ...................................... 16, 44

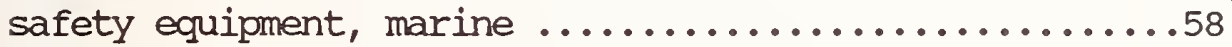

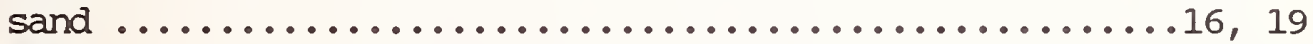

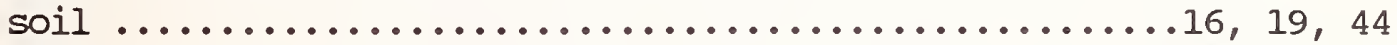

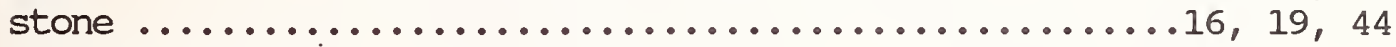

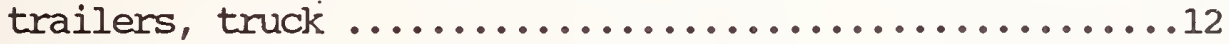

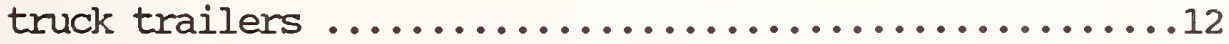

vehicles, light duty on-highway transportation ........28

workplace products, electrical and other ...........52 


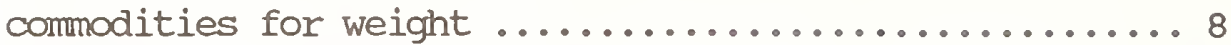

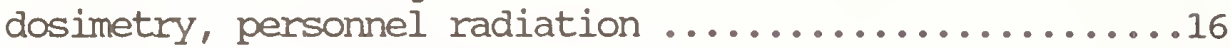

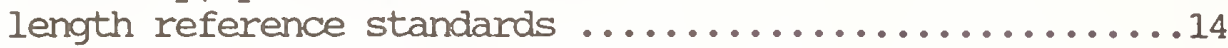

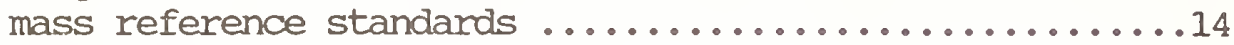

measurement equipment/systems .................. 8, 14

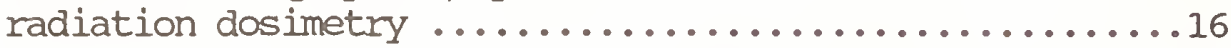

temperature (Iiquid in-glass) reference standards .....14

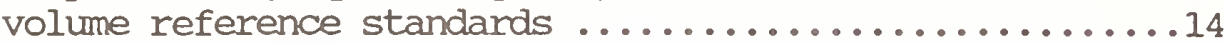

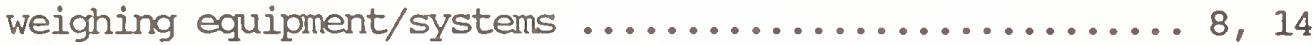

MISC. PRODUCTS

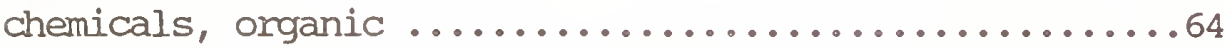

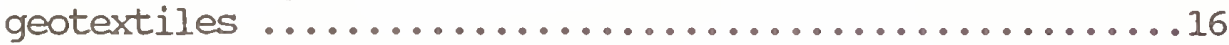

military devices and components $\ldots \ldots \ldots \ldots \ldots \ldots \ldots . \ldots \ldots \ldots . \ldots \ldots$

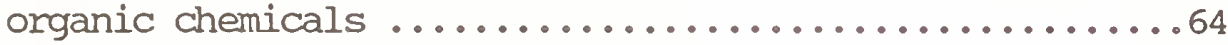

petroleum and petroleum products .................64 


\section{APPENDIX II \\ FORTAT USFED FOR FACH ENITYY}

Received:

Department/Agency: The responsible office/agency/department, as well as their address, telephone, telex, and fax numbers if available.

Program Title: Designation identifying the program or part of the program responsible for laboratory accreditation.

Date Established: The date the program was begun.

Description: Brief description of the scope and intent of the program.

Fields of Testing: The fields of testing covered by the program, including: acoustic/vibration measurement, biological, chemical, electrical, ionizing radiation, mechanical, metrology, non-destructive, optics and photometry, thermal, and other fields as indicated by the agency.

Products Tested: The products/services which laboratories are accredited to test.

Standards/Test Methods:

Assessment

Criteria/

Procedures:
The documents employed by the accrediting agency to define the terms of accreditation.

The criteria/procedures used by the program to ensure the competence of a laboratory to conduct a test or set of tests. including:

Submission of Appropriate Documentation

Independence (No Conflict-of-Interest)

Financial stability

on-site Inspection

Staff qualifications Requirements

Adequate Q.A. System

Sample Control/Integrity Requirements

Recordkeeping Requirement's

Test Report Content/Format Requirements

Available operational Manuals/Instructions

Periodic Random Re-audit of Facilities

Periodic Scheduled Re-audit of Facilities

Participation in a Proficiency Testing Program

Adequacy of Facilities \& Equipment

Equipment Maintenance/Calibration Requirements

other

Other Information: Any other relevant information on the criteria/procedures used in the program.

Accreditation

Terminology:

Compliance:
Term(s) used by the accrediting authority to refer to a laboratory which has met the accreditation criteria.

Whether the program is mandatory, voluntary, or mandatory only under specified circumstances. 
Authority:

Fees:

\section{Accreditation}

Action Frequency:

Assessors:

Proficiency

Testing Program:

Appeal Procedure:

Publications:

Logo:

NN. of Labs:

Availability of Aocreditation:

Iist/Directory of Aocredited Ialos:

Int'1 Recogmition/ Any recognition of the accreditation by foreign governments Agreements: or international organizations or agreements between the United States and other country(s) on mutual recognition of accredited laboratories or test results from accredited laboratories.

Other Recognition: Any recognition of the accreditation by other federal or state agencies, or private sector organizations. 
Parties interested in this area may wish to review NBS SP 739, Directory of Federal Government Certification Programs, which contains information on a number of closely related programs. In addition, the following information is provided on current and proposed federal programs which also in designate laboratories in some manner. The agencies, however, do not consider the programs to be operational laboratory accreditation/designation programs.

Agricultural Marketing Service, USDA, Accreditation of laboratories and certification of laboratory analysts for AMS - UNDER DEVEIOPMENT.

Rural Electrification Administration, USDA, Requirements for the inspection of treated wood products by independent third-party inspection agencies.

National Institute of Standards and Technology, Law Enforcement Standards Laboratory (LESL), DOC, TAPIC contracts.

Office of Atmospheric \& Indoor Air Programs, EPA, Survey of Indoor Air Assessment/Mitigation Firms.

Federal Supply Service, GSA, A new program is being established by GSA for Federal supply Service Schedule 71-III M - Acoustical/Speech Privacy Partitions.

Food and Drug Administration, DHHS, National Shellfish Sanitation Program (NSSP)

Federal Housing Administration, HUD, Recognition of laboratories accredited by the National Voluntary Laboratory Accreditation Program (NVLAP) and the American Association for Laboratory Accreditation (A2LA) .

Mine Safety \& Health Administration, DOL, Mine-Wide Monitoring Systems Program.

Mine Safety \& Health Administration, DOL, Diesel Test Program.

Federal Aviation Administration, Dor, Airport lighting equipment manufacturers entered into an aviation equipment certification program with an independent testing laboratory that was selected and is paid for by the manufacturers.

Federal Aviation Administration, Dor, Recognition of the use of a third-party accreditation program by holders of FAA Production Approval Certification (PC), Parts Manufacturer Approval (PMA), Technical Standards Order Authorization (TSOA) or Approved Procuction Inspection System (APIS) under certain conditions.

National Highway Traffic Safety Administration, Dor, Contracts with laboratories capable of conducting vehicle safety related testing.

Prosthetic \& Sensory Aids Service, VA, Certification of equipment is made by the VA sponsored Automobile Adaptive Equipment or Prosthetic Technology Equipment committees. Test results used include those from approved laboratories. 
Department/Agency: Department of Agriculture (USDA)

Agricultural Marketing Service (AMS)

Commodities Scientific Support Division (CSSD)

P.O. Box 96456

Room 3521 South Building

Washington, DC 20090-6456

Program Title: Accreditation of laboratories and certification of laboratory analysts for AMS - UNDER DEVELOPMENT.

Date Established: Several programs currently under development.

Description: While AMS does not currently have any laboratory accreditation programs, AMS has received requests from the dairy industry regarding the accreditation of laboratories to perform testing of dairy products. A program to accredit laboratories to test for salmonella in dried and liquid egg products is also under consideration. CSSD has been assigned responsibility for the accreditation of laboratories and certification of laboratory analysts for AMS. CSSD also works with various other food commodity industries and will, at their request, consider laboratory accreditation programs in other areas.

In addition, under a 1990 farm bill, USDA may be required to establish a accreditation program in conjunction with FDA to accredit laboratories that test foods for pesticide residues.

Products Tested: Dairy products, egg products, food commodities, food products for pesticide residues.

Department/Agency: Department of Commerce (DOC)

National Institute of Standards and Technology (NIST)

Law Enforcement Standards Laboratory (LESL)

Building 224, B116

Gaithersburg, MD 20899

Phone: $\quad$ (301) $975-2757$

FAX: $\quad$ (301) $975-7434$

Program Title: TAPIC contracts.

Description: Under an NIJ contract, the Aspen Systems corporation has operated a limited equipment testing program through the Technology Assessment Program Information center (TAPIC). Where LESL and the National Institute of Justice (NIJ), U.S. Department of Justice sponsor the testing of specific items of law enforcement equipment, LESL assists in the preparation of the request for proposal from testing laboratories and the evaluation of the resulting bids to tentatively select two independent laboratories for each item of equipment to be tested. Following the award of the two contracts, IESL, TAPIC, and members of the National Voluntary Laboratory Accreditation Program (NVLAP) visit the laboratories for an on-site facility investigation and witness the complete 
testing of one item of equipment. When the inspection team is satisfied that the laboratory personnel are proficient in testing to the LESL-developed standards, that all test equipment is properly calibrated, maintained and operated, and that all appropriate test records are maintained, the TAPIC classifies the laboratory as a certified laboratory for that item of equipment.

Products Tested: Law enforcement equipment.

Department/Agency: Department of Agriculture (USDA)

Rural Electrification Administration (REA)

Electric Staff Division

Room 1272 S. Agriculture Bldg. Independence Ave. bet. 12th \& 14th Sts., SW Washington, DC 20250

Phone: (202) 382-9086

Description: $\quad$ REA maintains requirements for the inspection of treated wood products by independent third-party inspection agencies, but no longer maintains a list of approved agencies. Each electric cooperative is responsible for assuring that the agencies they use have the qualifications and experience required by REA.

Products Tested: Forestry products.

Department/Agency: Enviromental Protection Agency (EPA)

Assistant Administrator for Air and Radiation

office of Atmospheric \& Indoor Air Programs

Indoor Air Division (AMR-445)

West Tower of Waterside Mall, W-735

401 M Street, SW

Washington, DC 20460

Phone: $\quad 202-475-8470$

FAX: $\quad 202-382-7991$

Program Title: Survey of Indoor Air Assessment/Mitigation Firms.

Description: Surveys firms which assess the quality of air inside buildings and conduct mitigation services.

Fields of Testing: Chemical, microbiological, climatic conditions.

Products Tested: Air.

Other Information: Information is reported by the firm. No evaluation of that information is conducted.

Compliance: Voluntary. 
Authority:

Fees:

Appeal Procedure: N/A.

Publications: $\quad$ EPA publishes a "Survey of Indoor Air Quality Diagnostic and Mitigation Firms," which is a list of firms which have responded to the survey.

Logo: None.

List/Directory of "Survey of Indoor Air quality Diagnostic and Mitigation Accredited Labs: Firms."

Department/Agency: General Services Administration (GSA)

Federal Supply Service (FSS)

Furniture commodity Center (FCNE)

Bldg. 4, Crystal Mall

Arlington, VA 22202

Phone: $\quad 703-557-8473$

FAX: $\quad 703-557-0032$

Description: A new program is being established by GSA for Federal Supply Service Schedule 71-III M - Acoustical/Speech Privacy Partitions. Under this program, all contractors will be required to enter into an agreement with a GSA accepted laboratory or certifying body before a contract will be awarded.

Products Tested: Acoustical/Speech Privacy Partitions

standards/Test Federal specifications and all referenced standards and test Methods:

Compliance: methods applicable.

Voluntary for certification bodies/laboratories; mandatory for manufacturers trying to meet procurement requirements of the FSS.

Fees: None by FSS.

Publications: Specific federal specifications in which requirements are described as well as federal procurement regulations are available.

Logo:
The listing/label of the accepted laboratory/certification body 
Department/Agency: Department of Health and Human Services

Food and Drug Administration (FDA)

Center for Food Safety and Applied Nutrition

(HFF-232)

200 C Street, SW

Washington, D.C. 20204

Phone:

(202) 245-1221 or 245-1231

Program Title: National Shellfish Sanitation Program (NSSP)

Description: $\quad$ A 2-month pilot program conducted jointly by FDA and NOAA will begin October 1, 1990. Plans for this voluntary program may be obtained from the National Seafood Inspection Laboratory, P.O. Drawer 1207 Pascagoula, MS 39567. FDA contact is: John Kvenber, or George Hoskin ( $\mathrm{HFF}-400)$, Center for Food Safety and Applied Nutrition (HFF-232), FDA, 200 C Street, SW, Washington, DC 20204 (202) 245-1221 or 245-1231. Under the old program, FDA evaluated state and local laboratories used for the examination of sea water and shellfish. The laboratories are only evaluated for compliance with American Public Health Association (APHA) procedures for the examination of sea water and shellfish, not approved or certified.

Products Tested: Shellfish.

Standards/Test Methods:

National Shellfish Sanitation Program (NSSP) criteria and Good Manufacturing Practice Regulations, American Public Health Association (APHA) Procedures.

Publications: FDA publishes monthly the "Interstate certified Shellfish Shippers List" (ICSSL) containing the names and certification numbers of state certified shellfish firms.

Department/Agency: Department of Housing and Urban Development (HUD) Office Manufactured Housing and Regulatory Functions Room 6270 451 Seventh Street, SW washington, DC $20410-8000$

Description: $\quad$ Program recognizes laboratories accredited by the National Voluntary Iaboratory Accreditation Program (NVLAP) and the American Association for Laboratory Accreditation (A2LA) .

Products Tested: Building construction products and components. 
Department/Agency: Departiient of Labor (DOL)

Mine Safety \& Health Administration (MSHA)

Approval \& Certification Center (A\&CC)

RRI, Box 251

Industrial Park Road

Triadelphia, WV 26059

Phone: $\quad$ (304) $-547-0400$ FTS: 723-1501

Date Established: 1981.

Program Title: Mine-Wide Monitoring Systems Program.

Description: MSHA accepts data from laboratories on intrinsic safety of barriers and sensors. MSHA reserves the right to retest.

Products Tested: Barriers and sensors.

Department/Agency: Department of Labor (DOL)

Mine Safety \& Health Administration (MSHA)

Approval \& Certification Center (A\&CC)

RRI, Box 25!

Industrial Park Road

Triadelphia, WV 26059

Phone: $\quad(304)-547-0400$ FTS: $723-1501$

Program Title: Diesel Test Program.

Description: MSHA allows for the testing of diesel engines for emissions at an outside laboratory. MSHA witnesses all tests and is the approval authority.

Products Tested: Diesel engines.

Department/Agency: Department of Transportation (DOT)

Federal Aviation Administration (FAA)

Office of Airports

Engineering and Specifications Division

800 Independence Avenue, SW

washington, DC 20591

Phone: $\quad 202-267-3053$

Description: As of 1/1/90, airport lighting equipment manufacturers entered into a certification program with an independent testing laboratory selected and paid for by the manufacturers. The FAA continues to publish a list of approved equipment based on the findings of that laboratory.

Products Tested: Airport lighting 
Department/Agency: Department of Transportation (DOT)

Federal Aviation Administration

Aircraft Certification Service, AIR-1, Room 300W

800 Independence Ave., SW

Phone:

Washington, DC 20591

Description:

703-267-8235

The FAA recognizes the use of a third-party accreditation program by a holder of a FAA Production Approval certification (PC), Parts Manufacturer Approval (PMA), Technical Standards order Authorization (TSOA) or Approved Production Inspection System (APIS) under certain conditions. An action notice (A8120.8) dated June 4, 1990 defines conditions under which such use is acceptable. Manufacturers/suppliers must notify the cognizant FAA Manufacturing Inspection District or Satellite office in writing prior to the use of the thirdparty accreditation program. Implementation of a third-party accreditation program is subject to FAA review and approval.

Products Tested: Aircraft, aircraft parts and related products. Use of thirdparty accreditation programs is most common in areas such as nondestructive inspection sources, fasteners, and microcircuit suppliers.

Department/Agency: Department of Transportation (DOT)

National Highway Traffic Safety Administration (NHTSA)

Office of Vehicle Safety Compliance

Crashworthiness Branch

4007 th Street, SW

Washington, DC 20590

Description: Contracts with laboratories interested and capable of conducting vehicle safety related testing. Laboratories conduct testing to test procedures supplied as part of the contract. Standards for instrumentation and laboratory conduct are also part of the supplied test procedure. A list of the contract laboratories is available from the above address.

Products Tested: Motor vehicles.

Department/Agency Department of Veterans Affairs (VA)

Prosthetic \& Sensory Aids Service

810 Vermont Ave., NW

Washington, DC 20420

Phone:

(202) 233-2011

Date Established: Driving aids, March 27, 1975; wheelchair lifts, May 10, 1978. self-propelled wheelchairs, December 7, 1977; motorized wheelchairs, December 15, 1981. 
Description:

Products Tested:

Compliance:

Authority:

Publications:

Other

Recognition:
Certification of equipment is made by the VA sponsored Automobile Adaptive Equipment or Prosthetic Technology Equipment committees. Test results used include those from approved laboratories.

Automotive driving aids and automatic wheelchair lifts. Selfpropelled wheelchairs, motorized wheelchairs.

Mandatory only for purchases funded by the VA.

Title 38 USC 4101(c) (2), P.L. 91-666.

VA Circular 10-86-54, lists certified suppliers of wheelchair lift systems and hand controls, the General Services Administration's (GSA) Federal Supply Schedule for wheelchairs provides particulars for those products.

General Services Administration. 


\section{APPENDIX IV - LIST OF ACRONYS}

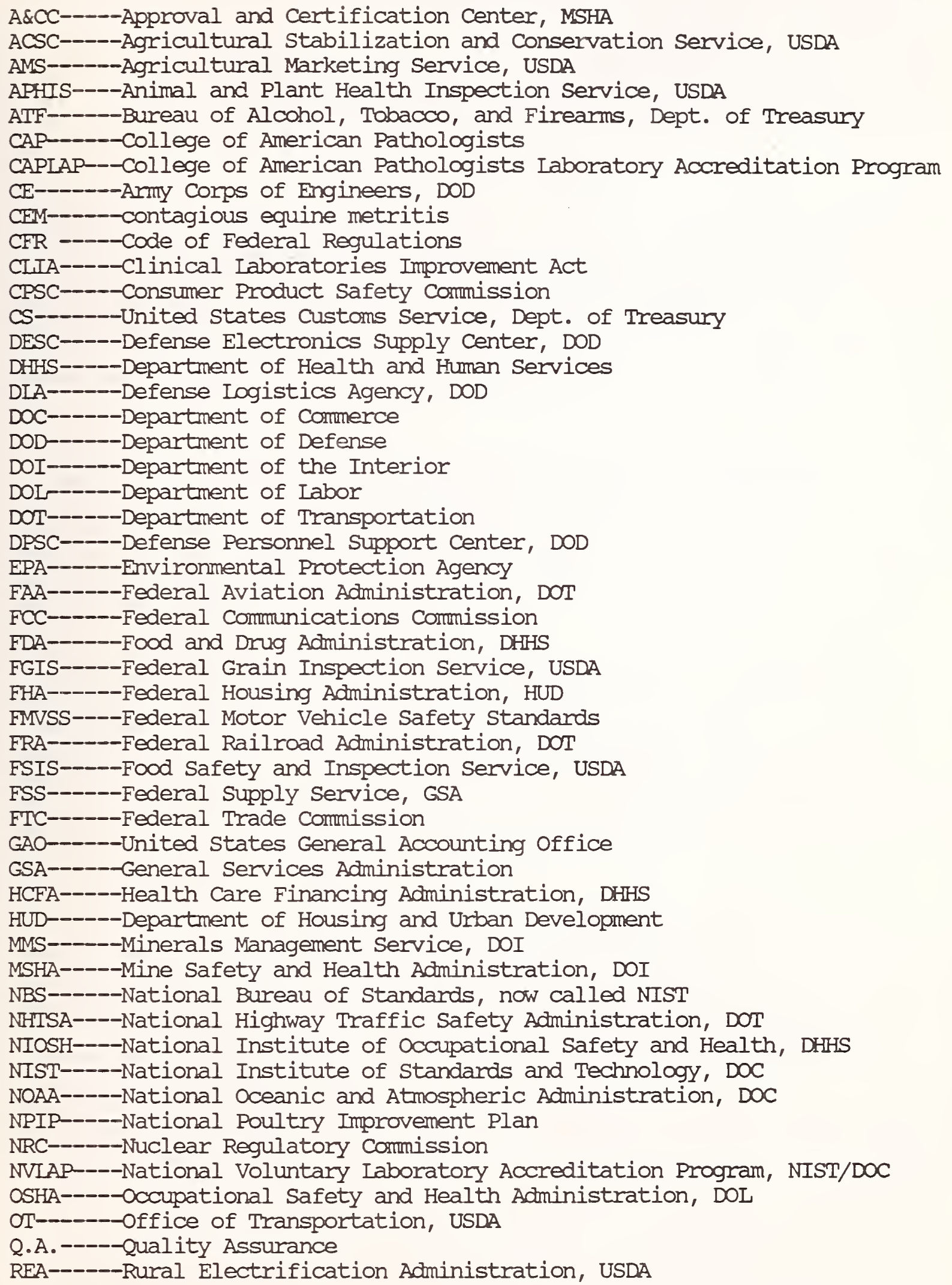


RSPA-----Research and Special Programs Administration, DOT

SOAP-----Small Operator Assistance Program

USDA-----United States Department of Agriculture

USGS-----United States coast Guard, DOT

VA------Department of Veterans Affairs

VHS\&RA---Veterans Health Services and Research Administration

VS-------Veterinary Service, USDA 


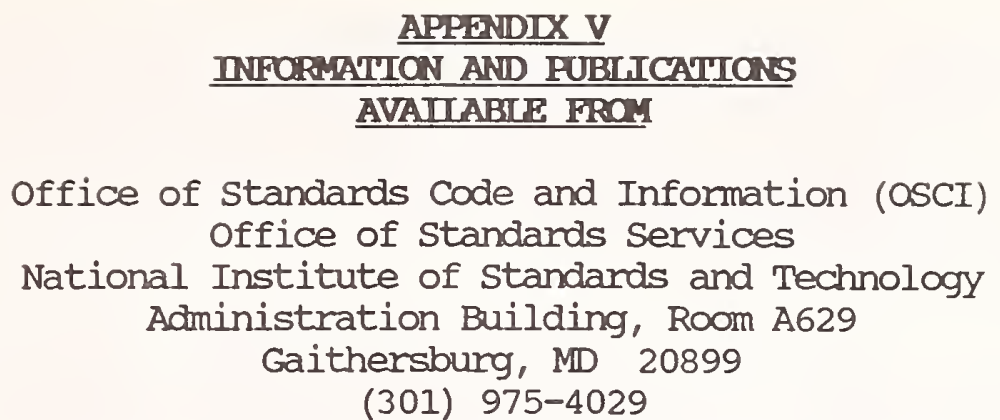

- The ABC's of Standards-Related Activities in the United States (NBSIR 87-3576) This report provides an introduction to voluntary standardization, product certification and laboratory accreditation for a reader who is not fully familiar with these topics. It highlights some of the more important aspects of these fields; furnishes the reader with both historical and current information on these topics; describes the importance and impact of the development and use of standards; and serves as background for using available documents and services. order as PB 87-224309 from NIIS.

- The ABC'S of Certification Activities in the United States (NBSIR 88-3821) This report, a sequel to NBSIR 87-3576, The ABC'S of Standards-Related Activities in the United States, provides a further introduction to certification for a reader who is not entirely familiar with this topic. It highlights some of the more important aspects of this field, furnishes the reader with information necessary to make informed purchases, and serves as background for using available documents and services.

order as PB 88-239793 from NTIS.

- Directory of International and Regional Organizations conducting Standards-Related Activities (NIST SP 767)

This directory contains information on 338 international and regional organizations which conduct standardization, certification, laboratory accreditation, or other standards-related activities. It describes their work in these areas, as well as the scope of each organization, national affiliations of members, U.S. participants, restrictions on membership, and the availability of any standards in English.

order as SN 003-003-02937-8 from GPO.

- Standards Activities of Organizations in the United States (NBS SP 806) The directory summarizes the standardization activities of more than 750 organizations in the United States, both federal and private sector, that develop standards, work with others to develop and use standards, regularly comment on draft standards, or which provide information on and distribute standards. It contains listings of sources of standards documents and information, a subject index and related listings that cover acronyms and initials, defunct bodies and organizations with name changes.

order from GPO or NIIS. Copies can also be purchased from Global Engineering Documents, 2805 MoGaw Ave., P.O. Box 19539, Irvine, CA 92714; (714) 261-1455. 
- Directory of Private Sector Product Certification Programs (NIST SP 774)

This directory presents information from 132 private sector organizations in the United States which engage in product certification activities. Entries describe the type and purpose of each organization, the nature of the activity, product certified, standards used, certification requirements, availability and cost of services, and other relevant details.

Order as SN 003-003-02984-0 from GPO.

- Directory of Federal Govermment Certification Programs (NBS SP 739)

This directory presents information on U.S. Govermment certification programs for products and services. Entries describe the scope and nature of each certification program, testing and inspection practices, standards used, methods of identification and enforcement, reciprocal recognition or acceptance of certification, and other relevant details.

Order as SN 003-003-02852-5 from GPO.

- Barriers Encountered by U.S. Exporters of Telecomunications Equipment (NBSIR 87-3641)

This report addresses the perceived institution of unreasonable technical trade barriers by major European trading partners to the export of telecom products and systems by U.S. companies. The GATT technical office, which has responsibilities to assist U.S. exporters to take advantage of trade opportunities, informally contacted over a period of six months, telecom companies and agencies to assess the extent of unreasonableness in foreign national standards, regulations, testing and certification requirements, and accreditation procedures. Order as PB 88-153630 from NTIS.

- A Review of U.S. Participation in International Standards Activities (NBSIR 883698)

This report describes the role of international standards, their increasingly significant importance in world trade, and the extent of past and current U.S. participation in the two major international standardization bodies - ISO and IEC. The degree of U.S. participation covers the 20 year period 1966-1986. A coarse analysis of data indicates some correlation between U.S. participation and recent export performance for several major product categories.

Order as PB 88-164165 from NIIS.

- An Update of U.S. Participation in International Standards Activities (NISTIR 89-4124)

This report presents updated information on the current level of U.S. participation in ISO and IEC (reference: NBSIR 88-3698). order as PB 89-228282/AS from NTIS.

- A Summary of the New European Community Approach to Standards Development (NBSIR 88-3793-1)

This paper summarizes European Community (EC) plans to aggressively pursue its goal of achieving an "internal market" by 1992 and the standards-related implications of such a program on U.S. exporters. Order as PB 88-229489/AS from NTIS. 
- Trade Implications of Processes and Production Methods (PPMs) (NISTIR 90-4265)

This report discusses processes and production methods (or PPM's) and their relationship to trade, the GATT Agreement on Technical Barriers to Trade, and traditional product standards used in international commerce. The report provides background information on PPM's, a suggested definition, and the possible extension of their application from the agricultural sector to industrial products.

Order as PB 90-205485 from NTIS.

- Directory of European Regional Standards-Related Organizations (NIST SP 795)

This publication contains information on European regional organizations which are involved in standardization, certification, laboratory accreditation, or other related activities. The directory describes their work in these areas, as well as other information of interest.

order as SN 003-003-03038-4 from GPO.

[SEE IAST PAGE FOR NTIS AND GPO CONTACTS]

The following documents are available upon request from the OSCI office.

- tbt news

This newsletter provides information on government programs and available services established in support of the GATT Agreement on Technical Barriers to Trade (Standards code). tbt news reports on the latest notifications of proposed foreign regulations; bilateral consultations with major U.S. trade partners; programs of interest to U.S. exporters; and availability of standards and certification information. Subscription is free upon request.

- Technical Barriers to Trade

This booklet explains the basic nules of the international Agreement on Technical Barriers to Trade negotiated during the Tokyo Round of the Multilateral Trade Negotiations (MTN), and describes Title IV of the U.S. Trade Agreements Act of 1979 which implements the United States' obligations under the Agreement. The Agreement, popularly known as the standards code, was designed to eliminate the use of standards and certification systems as barriers to trade. The booklet describes the functions of the Departments of Commerce and Agriculture, the Office of the U.S. Trade Representative, and the State Department in carrying out the U.S.'s responsibilities.

- "GATT Standards code Activities"

This brochure gives a brief description of NIST's activities in support of the Standards code. These activities include operating the U.S. GATT inquiry point for information on standards and certification systems; notifying the GATT Secretariat of proposed U.S. regulations; assisting U.S. industry with trade-related standards problems; responding to inquiries on foreign and U.S. proposed regulations; and preparing reports on the standard code. 
- GATT Standards code Activities of the National Institute of standards and Technology

This annual report describes the GATT Standards code activities conducted by the Office of Standards Code and Information for each calendar year. NIST responsibilities include operating the GATT inquiry point, notifying the GATT Secretariat of proposed U.S. Federal government regulations which may affect trade, assisting U.S. industry with standards-related trade problems, and responding to inquiries about proposed foreign and U.S. regulations.

- Report to the United States Congress on the Agreement on Technical Barriers to Trade - "Standards Code"

This triennial report describes the programs and activities established to implement the Standards Code in the United States by the four responsible U.S. government agencies: Office of the U.S. Trade Representative; Department of Commerce (National Institute of Standards and Technology, Intermational Trade Administration); Department of Agriculture and Department of State.

- Free handout material on office activities and standards-related information such as: govermment sources of specifications and standards; foreign standards bodies; U.S. standards organizations; and a brochure on the National center for Standards and Certification Information (NCSCI).

In addition to general inquiry services, the following assistance is also available:

- EC Hotline

This hotline reports on draft standards of the European committee on Standardization (CEN), the European Committee for Electrotechnical Standardization (CENELEC), and the European Telecommunications Standards Institute (ETSI). It also provides information on selected EC directives. The recorded message is updated weekly and gives the document number, product, and closing date for comments. The hotline number is (301) 921-4164 (not toll-free).

\section{- GATT Hotline}

A telephone hotline provides current information received from the GATT Secretariat in Geneva, Switzerland, on proposed foreign regulations which may significantly affect trade. The recorded message is updated weekly and gives the product, country, closing date for comments (if any) and Technical Barriers to Trade (TBT) notification number. The hotline number is (301) 975-4041 (not toll-free).

- NCSCI provides assistance to U.S. and foreign exporters in obtaining current standards, regulations and certification information for the manufacture of products. To aid foreign exporters, NCSCI also provides directory information of state offices prepared to respond to queries concerning conditions to be met by goods for sale in their state. 


\section{Publication ordering Information}

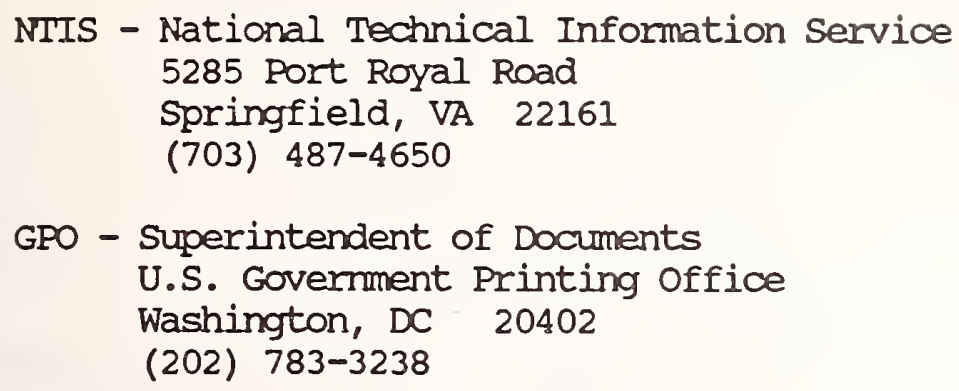




\section{BIBLIOGRAPHIC DATA SHEET}

\section{TITLE AND SUBTITLE}

Directory of Federal Government Laboratory Accreditation/Designation Programs

5. AUTHOR(S)

Maureen Breitenberg, Editor

6. PERFORMING ORGANIZATION (IF JOINT OR OTHER THAN NIST, SEE INSTRUCTIONS)

U.S. DEPARTMENT OF COMMERCE NATIONAL INSTITUTE OF STANDARDS AND TECHNOLOGY GAITHERSBURG, MD 20899

9. SPONSORING ORGANIZATION NAME AND COMPLETE ADDRESS (STREET, CITY, STATE, ZIP) National Voluntary Laboratory Accreditation Program (NVLAP) Technology Services National Institute of Standards and Technology Gaithersburg, MD

10. SUPPLEMENTARY NOTES

DOCUMENT DESCRIBES A COMPUTER PROGRAM; SF-185, FIPS SOFTWARE SUMMARY, IS ATTACHED.

11. ABSTRACT (A 200-WORD OR LES SACTUAL SUMMARY OF MOST SIGNIFICANT INFORMATION. IF DOCUMENT INCLUDES A SIGNIFICANT BIBLIOGRAPHY OP. LITERATURE SURVEY, MENTION IT HERE.)

This directory is designed to provide updated information on federal government laboratory accreditation and similar type programs conducted by the federal government. These programs designate a set of laboratories or other entities to conduct testing to assist federal agencies in carrying out their responsibilities. The programs generally include some assessment regarding the capability of the lab to conduct the testing. The type and degree of such assessments, however, vary greatly by program. It should be noted that the entries in this directory are based primarily on information provided by the federal agency and reflect the agency's view of its activities. Parties interested in this area may also wish to review NBS SP 739, Directory of Federal Government Certification Programs, which contains information on a number of closely related programs.

This directory is part of ongoing NIST efforts to establish and maintain comprehensive databases on standards, regulations, laboratory accreditation and certification programs and related information in accordance with the requirements of the Trade Agreements Act of 1979. This material has been compiled to meet the needs of government, industry, and the public for information on. U.S. Govemint lakeratory accreditation and related ro rams.

12. KEY WORDS (6 TO 12 ENTRIES; ALPHABETICAL ORDER; CAPITALIZE ONLY PROPER NAMES; AND SEPARATE KEY WORDS BY SEMICOLONS) certification; grading; inspection; laboratory accreditation; listing; mutual recognition schemes; proficiency testing; qualified laboratories; standards; testing FOR OFFICIAL DISTRIBUTION. DO NOT RELEASE TO NATIONAL TECHNICAL INFORMATION SERVICE (NTIS). ORDER FROM SUPERINTENDENT OF DOCUMENTS, U.S. GOVERMMENT PAINTING OFFICE, WASHINGTON, DC 20402. ORDER FROM NATIONAL TECHNICAL INFORMATION SERVICE (NTIS), SPRINGFIELD, VA 22161.

\section{5}

\section{PRICE}





\section{$\overline{\text { NIST }}_{\text {Trectrical Prabication }}$}

\section{Periodical}

Journal of Research of the National Institute of Standards and Technology-Reports NIST research and development in those disciplines of the physical and engineering sciences in which the Institute is active. These include physics, chemistry, engineering, mathematics, and computer sciences. Papers cover a broad range of subjects, with major emphasis on measurement methodology and the basic technology underlying standardization. Also included from time to time are survey articles on topics closely related to the Institute's technical and scientific programs. Issued six times a year.

\section{Nonperiodicals}

Monographs-Major contributions to the technical literature on various subjects related to the Institute's scientific and technical activities.

Handbooks-Recommended codes of engineering and industrial practice (including safety codes) developed in cooperation with interested industries, professional organizations, and regulatory bodies.

Special Publications-Include proceedings of conferences sponsored by NIST, NIST annual reports, and other special publications appropriate to this grouping such as wall charts, pocket cards, and bibliographies.

Applied Mathematics Series-Mathematical tables, manuals, and studies of special interest to physicists, engineers, chemists, biologists, mathematicians, computer programmers, and others engaged in scientific and technical work.

National Standard Reference Data Series-Provides quantitative data on the physical and chemical properties of materials, compiled from the world's literature and critically evaluated. Developed under a worldwide program coordinated by NIST under the authority of the National Standard Data Act (Public Law 90-396). NOTE: The Journal of Physical and Chemical Reference Data (JPCRD) is published quarterly for NIST by the American Chemical Society (ACS) and the American Institute of Physics (AIP). Subscriptions, reprints, and supplements are available from ACS, 1155 Sixteenth St., NW., Washington, DC 20056.

Building Science Series-Disseminates technical information developed at the Institute on building materials, components, systems, and whole structures. The series presents research results, test methods, and performance criteria related to the structural and environmental functions and the durability and safety characteristics of building elements and systems.

Technical Notes-Studies or reports which are complete in themselves but restrictive in their treatment of a subject. Analogous to monographs but not so comprehensive in scope or definitive in treatment of the subject area. Often serve as a vehicle for final reports of work performed at NIST under the sponsorship of other government agencies.

Voluntary Product Standards-Developed under procedures published by the Department of Commerce in Part 10, Title 15, of the Code of Federal Regulations. The standards establish nationally recognized requirements for products, and provide all concerned interests with a basis for common understanding of the characteristics of the products. NIST administers this program as a supplement to the activities of the private sector standardizing organizations.

Consumer Information Series-Practical information, based on NIST research and experience, covering areas of interest to the consumer. Easily understandable language and illustrations provide useful background knowledge for shopping in today's technological marketplace.

Order the above NIST publications from: Superintendent of Documents, Government Printing Office, Washington, DC 20402.

Order the following NIST publications-FIPS and NISTIRs-from the National Technical Information Service, Springfield, VA 22161.

Federal Information Processing Standards Publications (FIPS PUB)-Publications in this series collectively constitute the Federal Information Processing Standards Register. The Register serves as the official source of information in the Federal Government regarding standards issued by NIST pursuant to the Federal Property and Administrative Services Act of 1949 as amended, Public Law 89-306 (79 Stat. 1127), and as implemented by Executive Order 11717 (38 FR 12315, dated May 11, 1973) and Part 6 of Title 15 CFR (Code of Federal Regulations).

NIST Interagency Reports (NISTIR)-A special series of interim or final reports on work performed by NIST for outside sponsors (both government and non-government). In general, initial distribution is handled by the sponsor; public distribution is by the National Technical Information Service, Springfield, VA 22161, in paper copy or microfiche form. 
U.S. Department of Commerce

National Institute of Standards and Technology

(formerly National Bureau of Standards)

Gaithersburg, MD 20899

Official Business

Penalty for Private Use $\$ 300$ 